\title{
A COMPARATIVE SERIAL ECHOCARDIOGRAPHIC ANALYSIS OF CARDIAC STRUCTURE AND FUNCTION IN RATS SUBJECTED TO PRESSURE OR VOLUME OVERLOAD
}

\author{
BY \\ ELLIOTT J. F. CANTOR \\ A thesis submitted to the \\ University of Manitoba \\ In partial fulfillment of the requirements for the degree of

\section{MASTER OF SCIENCE} \\ Department of Physiology \& Faculty of Medicine \\ Institute of Cardiovascular Sciences \\ St. Boniface General Hospital Research Centre \\ Winnipeg, Manitoba
}

(C) Elliott J. F. Cantor, March 2005 


\title{
THE UNIVERSITY OF MANITOBA \\ FACULTY OF GRADUATE STUDIES \\ $* * * * *$ \\ COPYRIGHT PERMISSION PAGE
}

\begin{abstract}
A Comparative Serial Echocardiographic Analysis of Cardiac Structure and Function in Rats Subjected to Pressure or Volume Overload
\end{abstract}

BY

\author{
Elliott J.F. Cantor
}

\begin{abstract}
A Thesis/Practicum submitted to the Faculty of Graduate Studies of The University of Manitoba in partial fulfillment of the requirements of the degree

of

MASTER OF SCIENCE
\end{abstract}

ELLIOTT J.F. CANTOR $@ 2005$

Permission has been granted to the Library of The University of Manitoba to lend or sell copies of this thesis/practicum, to the National Library of Canada to microfilm this thesis and to lend or sell copies of the film, and to University Microfilm Inc. to publish an abstract of this thesis/practicum.

The author reserves other publication rights, and neither this thesis/practicum nor extensive extracts from it may be printed or otherwise reproduced without the author's written permission. 


\section{ACKNOWLEDGEMENTS}

I would like to thank my supervisor Dr. Thomas Netticadan who gave me an opportunity to pursue my research goals and offered me great insight into cardiovascular physiology. I value your kind heart, expertise and mentorship, and I know that I have learned some valuable lessons that I will take with me for the rest of my life. I would also like to acknowledge my committee members Dr. Ian Dixon, Dr. Elissavet Kardami and Dr. Jeffrey Wigle. Your continued support over the last few years has helped focus my research and guide it in the right direction. I am thankful for your diligent review of my thesis and all of your encouraging words.

My sincere thanks go out to all of my colleagues with whom I have had the privilege of working, collaborating and making friends. It goes without saying that none of my time in R3042 would have been as exciting without all of you: Dr. Xing-Hai Yao, Dr. Satyajeet Rathi, Mellissa Moyen, Raja Singh, Punam Chohan, Andrea Babick, Zainisha Vasanji, Danijel Juric, Jason Greville, Rishi Seth, John Babick, Enrico Mancini and Fuwu Bai. I wish you all the best in your current and future endeavours. I have also enjoyed getting to know my other colleagues at the Institute of Cardiovascular Sciences. Thank you for all of your support.

The University of Manitoba's Department of Physiology has been instrumental in my progress and development as a student. Thank you to Dr. Peter Cattini and Dr. Janice Dodd who have served as model department heads during 
my time in Physiology. Many thanks to Gail McIndless and Judith Olfert for taking care of all the paper work associated with the program.

Finally, I would like to thank my family and friends for their unwavering love and encouragement throughout the struggles and successes of my research. I am forever grateful to have you all in my life. 


\section{TABLE OF CONTENTS}

Page

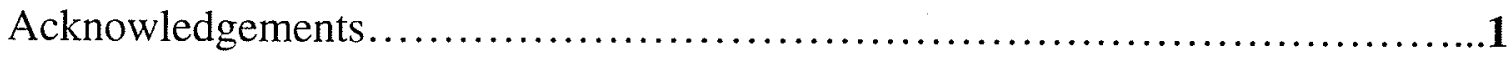

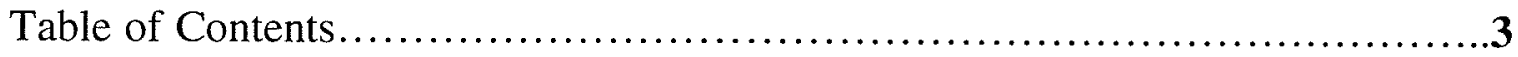

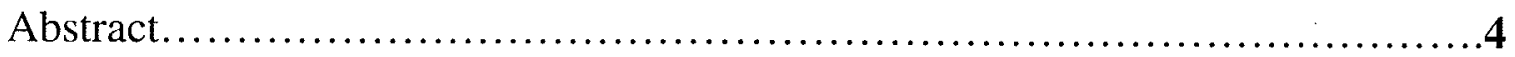

List of Abbreviations......................................................

List of Tables..............................................................

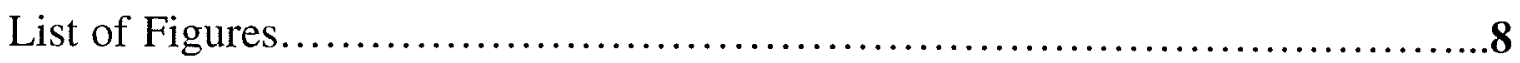

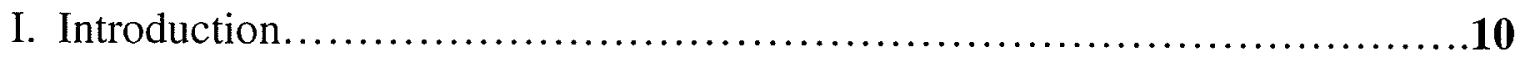

II. Literature Review...................................................

2.1 Mortality and Morbidity Due to Heart Failure........................12

2.2 Modern Definition of Heart Failure....................................12

2.3 Causes of Heart Failure..............................................13

2.4 Physiological Aspects of Heart Failure..................................22

2.5 Biophysics and Biochemistry of Heart Failure.............................24

2.6 Alterations in Calcium Handling in Heart Failure........................27

2.7 Hypertrophy Defined................................................28

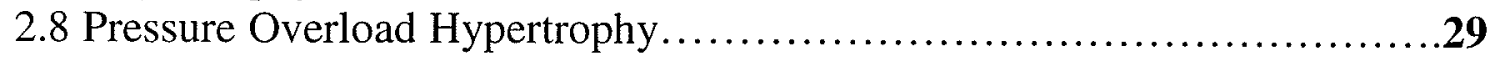

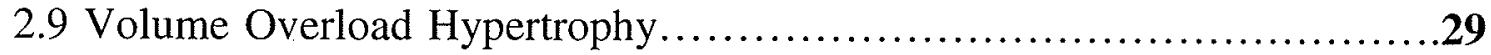

2.10 Adaptive Versus Maladaptive Left Ventricular Remodelling..............30

2.11 Experimental Models of Pressure \& Volume Overload-Induced Failure...32

2.12 Echocardiography: General Overview.................................34

2.13 Echocardiography and Hypertrophy ...............................35

III. Statement of Hypothesis...............................................38

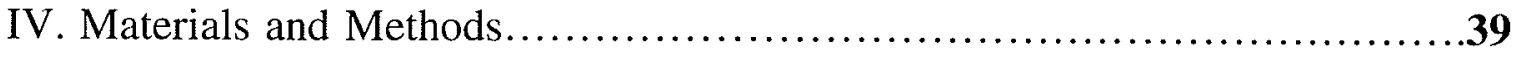

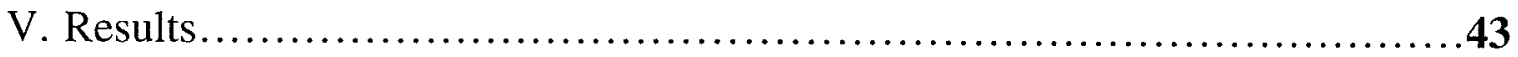

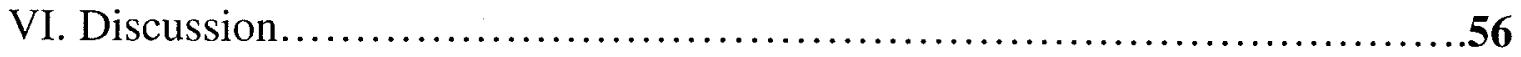

VII. References..........................................................64 


\begin{abstract}
Heart failure is a leading cause of death that is reaching epidemic proportions. It is a clinical syndrome attributable to a multitude of factors that begins with a compensatory response known as hypertrophy, followed by a decompensation that eventually results in failure. Heart failure may be triggered when the heart is subjected to chronic periods of pressure overload (PO) or volume overload (VO). To date there have been no comparative serial studies outliming the development and progression of hypertrophy in animals subjected to PO versus those subjected to VO. We hypothesized that PO or VO would induce differential left ventricular (LV) remodelling leading to cardiac contractile dysfunction with subsequent heart failure. To address this hypothesis we used echocardiography to study the serial progression of LV structure and function in experimental models of both PO- and VO-induced hypertrophy. PO or VO was induced in rats by performing abdominal aortic banding or aortocaval shunt procedures respectively. Also, LV structure and LV function were assessed in both models by M-mode and Doppler echocardiography at key time intervals. PO rats showed progressive wall thickening consistent with concentric hypertrophy, while VO rats showed marked LV dilatation consistent with eccentric hypertrophy. Systolic dysfunction occurred early in VO compared to PO. Diastolic dysfunction was evident in PO, while VO showed signs of enhanced diastolic function. PO and VO induced differential changes in LV structure and function during the progression of compensated hypertrophy to decompensated heart failure.
\end{abstract}




\section{LIST OF ABBREVIATIONS}

A wave - Peak late diastolic filling velocity

AEt - Aortic ejection time

ATP - Adenosine triphosphate

$\mathrm{Ca}^{2+}-$ Calcium or calcium ion(s)

CAD - Coronary artery disease

CHF - Congestive heart failure

$\mathrm{CI}$ - Cardiac index

$\mathrm{CO}$ - Cardiac output

DCM - Dilated cardiomyopathy

DHPR - L-type voltage-dependent (dihydropyridine sensitive) $\mathrm{Ca}^{2+}$ channels

E decel time - E deceleration time

E wave - Peak early diastolic filling velocity

$E F-$ Left ventricular ejection fraction

FS - Left ventricular fractional shortening

GPx - Glutathione peroxidase

$\mathrm{H}_{2} \mathrm{O}_{2}$ - Hydrogen peroxide

HBW - Heart-to-body weight

HCM - Hypertrophic cardiomyopathy

HR - Heart rate

IVRt - Isovolumic relaxation time

IVS - Interventricular septum

IVSd - Interventricular septum at diastole

IVSs - Interventricular septum at systole 
LV - Left ventricle or left ventricular

LVID - Left ventricular internal dimensions

LVIDd - Left ventricular internal dimensions at diastole

LVIDs - Left ventricular internal dimensions at systole

LVm - Left ventricular mass

LVPW - Left ventricular posterior wall

LVPWd - Left ventricular posterior wall at diastole

LVPWs - Left ventricular posterior wall at systole

$\mathrm{NCX}-\mathrm{Na}^{+} / \mathrm{Ca}^{2+}$ exchanger

NO - Nitric oxide radical

$\mathrm{O}_{2}^{-{ }^{-}-}$Superoxide anion

$\cdot \mathrm{OH}$ - Hydroxyl radical

$\mathrm{ONOO}^{-}$- Peroxynitrite

PLB - Phospholamban

PO - Pressure overload

ROS - Reactive oxygen species

RyR2 - Ryanodine receptor

SERCA2a - Sarco/endoplasmic reticulum calcium-ATPase

SOD - Superoxide dismutase

SR - Sarcoplasmic reticulum

$\mathrm{SV}$ - Stroke volume

TAC - Transverse aortic constriction

VO - Volume overload 


\section{LIST OF TABLES}

Table

Page

1. General characteristics of rats subjected to pressure overload (PO) .........47

2. General characteristics of rats subjected to volume overload (VO)..........48 


\section{LIST OF FIGURES}

Figure

Page

1. M-mode echocardiograms of representative left ventricles from sham (A), pressure overload (B) and volume overload (C) rats at 28 weeks....

2. M-mode echocardiographic measurements of diastolic dimensions (A, C, E) and systolic dimensions $(\mathrm{B}, \mathrm{D}, \mathrm{F})$ in pressure overload $(\mathrm{PO})$ and volume overload (VO). \# $\mathrm{P}<0.05$ vs. sham (PO); * $\mathrm{P}<0.05$ vs. sham (VO) .50

3. Fractional shortening (A) and ejection fraction (B) in pressure overload (PO) and volume overload (VO). \# $\mathrm{P}<0.05$ vs. sham $(\mathrm{PO}) ; * \mathrm{P}<0.05$ vs. sham (VO).

4. Cardiac output (A), cardiac index (B), heart rate (C) and stroke volume (D) in pressure overload (PO) and volume overload (VO). \# $\mathrm{P}<0.05$ vs. sham (PO);

$* \mathrm{P}<0.05$ vs. sham $(\mathrm{VO})$ .52

5. Linear regression analysis of left ventricular mass $(\mathrm{LVm})$ values versus wet heart weights collected at the 28 -week time point. PO, pressure overload; VO, volume overload .............................................53

6. Time course of diastolic parameters obtained by Doppler echocardiography in pressure overload (PO) and volume overload (VO). E wave, peak early diastolic filling velocity; A wave, peak late diastolic filling velocity; E/A, ratio of early to late peak diastolic filling velocities; $\mathrm{E}$ decel time, $\mathrm{E}$ deceleration time. \# $\mathrm{P}<0.05$ vs. sham $(\mathrm{PO}) ;{ }^{*} \mathrm{P}<0.05$ vs. sham (VO) 
7. Isovolumic relaxation time (IVRt) (A) and aortic ejection time (AEt) (B) in pressure overload (PO) and volume overload (VO) models obtained by Doppler echocardiography using the apical 5-chamber view. \# $\mathrm{P}<0.05$ vs.

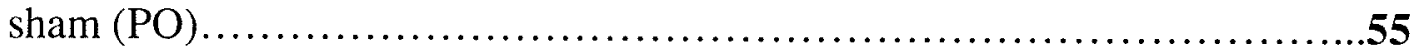




\section{INTRODUCTION}

Heart failure is the leading cause of mortality in the United States (1) and its incidence is projected to reach epidemic proportions (2). Approximately one in two people in the developed world will die from cardiovascular disease (3). Heart failure is a multifactorial syndrome wherein the heart's ability to pump sufficient blood to meet the metabolic demands of organs and tissues is compromised. Diseases such as hypertension, ischemic heart disease, valvular heart disease, cardiomyopathy, myocarditis (4) and diabetes (5) may lead to the development of heart failure. Regardless of the initial stimulus, the heart counters these insults with a mechanism known as hypertrophy - a compensatory enlargement of the heart - due to increased biomechanical stress (6).

Cardiac hypertrophy may be categorized into two broad types: that due to pressure overload (PO) or volume overload (VO). PO occurs in many clinical settings such as hypertension, mitral valve stenosis and aortic valve stenosis. When subject to one of these negative stimuli, the heart undergoes concentric remodelling in order to normalize wall stress that results from the increased pressure placed on the cardiac tissue. Concentric remodelling of the left ventricle (LV) involves the thickening of the septal and posterior walls via the replication of sarcomeres in parallel. Thus, an increase in pressure is offset by an increase in wall thickness (7). The other type of cardiac hypertrophy, VO, occurs due to anemia, heart block, regurgitant mitral or aortic valves, atrial or ventricular septal defects, or other congenital diseases. The response to one of these stimuli is 
eccentric hypertrophy, which results in dilatation of the LV and a concurrent elevation in stroke volume in order to compensate for excess blood volume delivered to, or remaining in, the LV. Dilatation of the LV chamber occurs via elongation of the surrounding myocytes - the result of sarcomeric replication in series (8).

To date, there have been very few studies that have addressed a detailed time course analysis of cardiac structure and function in either PO or VO experimental models of heart failure. Moreover, comparative analyses of PO and VO in the same animal species are lacking. Therefore, we sought to carry out a complete, detailed and comparative time course analysis of general characteristics, structure, as well as systolic and diastolic function of rat hearts that undergo POand VO-induced hypertrophy. We hypothesize that PO and VO lead to concentric and eccentric remodelling respectively, with subsequent cardiac contractile dysfunction leading to the early stages of heart failure. 


\section{LITERATURE REVIEW}

\section{$\underline{\text { Heart Failure }}$}

\subsection{Mortality and Morbidity Due to Heart Failure}

Heart failure is the leading cause of mortality in the United States (1) and worldwide (9). As well, it is the most common cause of morbidity and mortality in industrialized countries (10). Heart failure is increasing in incidence and prevalence (11) and it is projected to reach epidemic proportions (2). Moreover, the 5-year mortality rate due to heart failure is about 50\% (12) and approximately one in two people in the developed world will die from cardiovascular disease (3). The economic cost of cardiovascular disease in Canada has risen to $\$ 20$ billion each year (13). With the threat of heart failure reaching such staggering levels, the need for basic research of the mechanisms of cardiovascular disease is of paramount importance.

\subsection{Modern Definition of Heart Failure}

Heart failure is currently classified as a clinical syndrome, not merely a disease. Heart failure may arise due to a multitude of factors leading to many different clinical manifestations (14). Traditional definitions, which prevailed throughout most of the $20^{\text {th }}$ Century, defined heart failure as a hemodynamic disorder due to impairment or failure of the heart's pumping mechanism. Thus, increased pulmonary and systemic venous pressures, fluid retention and low cardiac output $(\mathrm{CO})$ were encompassed in such a definition (15). However, this merely covers a small aspect of heart failure as we know it today. It does not 
include critical aspects such as alterations in contractility, impairment of relaxation and abnormal proliferative signalling. Accepted definitions of heart failure in recent decades include aspects of organ physiology, biochemistry, biophysics, and gene expression. Katz (14) put forth a comprehensive definition of heart failure by describing it as "a clinical syndrome in which heart disease reduces $\mathrm{CO}$, increases venous pressures, and is accompanied by molecular abnormalities that cause progressive deterioration of the failing heart and premature myocardial cell death." Mann (16) also clearly states that heart failure may no longer be defined in simple hemodynamic terms. He feels that a more encompassing definition of heart failure involves "the summation of multiple anatomic, functional, and biological alterations that interact together in an exceedingly complex manner and in different genetic and environmental backgrounds over a sustained (but variable) period of time."

\subsection{Causes of Heart Failure}

Differences in physiological, biochemical, biophysical and proliferative effects that a failing heart may exhibit, depend chiefly on the root cause of the heart failure. Major causes of heart failure may be broadly categorized as: coronary artery disease, hypertension, cardiomyopathies and valvular heart disease. Other factors that lead to heart failure include lung disease, anemia, hyperthyroidism and arrhythmias (17). 


\subsubsection{Coronary Artery Disease}

Coronary artery disease (CAD) is the most common type of heart disease in western countries and is a leading cause of death in the United States (18). CAD may cause myocardial ischemia and its complications may result in myocardial infarction (19). Ischemia of the myocardium may occur due to vascular spasms of the coronary arteries, atherosclerotic plaques, thrombosis or thromboembolisms. While vascular spasm is reversible and is thought to occur due to the release of platelet activating factor from the endothelium as a result of reduced oxygen, atherosclerosis, thrombi and emboli (thromboembolisms) may cause severe myocardial damage. Atherosclerosis is a degenerative disease that leads to coronary arterial occlusion. Initially, cholesterol-rich lipids build up beneath the endothelial cells lining the artery. This is followed by the migration of smooth muscle cells from the muscular layer of the blood vessel onto and surrounding the lipid deposit. The resulting plaque interferes with the nutrient exchange between the blood and the endothelium, causing damage to the surrounding cells leading to the subsequent recruitment of fibroblasts and the formation of a connective tissue cap over the plaque. Gradual enlargement of the plaque eventually blocks coronary flow leading to myocardial ischemia. Also, the plaque may rupture exposing the collagen-rich connective tissue to blood platelets. This leads to the formation of a thrombus which can block blood flow or break off to form an embolus which can cause a thromboembolism by occluding a smaller downstream arterial vessel (18). In the laboratory, coronary ligation techniques are performed 
on small animals to model clinical CAD so as to study the development of myocardial infarctions.

\subsubsection{Hypertension}

Hypertension, or high blood pressure, may be of primary or secondary origins. The cause of primary hypertension remains unknown in most cases; however, a strong pattern of genetic inheritance is often associated with this pathological state. Furthermore, obesity, stress, smoking and salt intake may contribute to its development (18). Problems such as defective salt and water regulation by the kidneys, plasma membrane abnormalities, defective genes coding for angiotensinogen or an inactive hypothalamus may all cause primary hypertension. Secondary hypertension may be the result of atherosclerosis, a blockage of the renal artery, endocrine dysfunction or neurological lesions (18).

Hypertension is associated with both systolic and diastolic dysfunction (17) and is the most common cause of diastolic dysfunction leading to heart failure (20). Hypertension leads to both LV hypertrophy and fibrosis that causes reduced myocardial compliance (20).

\subsubsection{Cardiomyopathy}

Cardiomyopathy is defined as a disease of the heart muscle that is associated with cardiac dysfunction (21). Major forms of cardiomyopathies include dilated, hypertrophic, restrictive/obliterative and diabetic. 


\subsubsection{Dilated Cardiomyopathy}

Dilated cardiomyopathy (DCM) is the most common type of cardiomyopathy as well as the most common cause of congestive heart failure (CHF) (22). It may be of genetic origin $(21,23)$; due to infection from viruses (24), bacteria, fungi or parasite; alcohol or drug-induced or caused by a collagen disease during pregnancy. This condition results in left and/or right ventricular dysfunction, and eccentric hypertrophy (21) (See Section 2.9). CHF is often associated with LV systolic dysfunction and backward failure of the right ventricle (See section 2.4.5) leading to edema. Arrhythmias as well as mitral and/or tricuspid valve regurgitation may occur in patients with CHF (22). Approximately $30-40 \%$ of people with DCM have a genetic form, the majority of which are of autosomal dominant inheritance. X-linked, autosomal recessive and mitochondrial inheritance are far less common forms of DCM.

\subsubsection{Hypertrophic Cardiomyopathy}

Hypertrophic cardiomyopathy (HCM) is an uncommon autosomal dominant condition defined as LV hypertrophy in the absence of sufficient hemodynamic stress to cause such hypertrophy. It is caused by mutations in genes coding for sarcomeric proteins $(25,26)$ and may be diagnosed using echocardiography $(22,25,27)$. HCM causes thickening of the left ventricular posterior wall (LVPW) and interventricular septum (IVS) resulting in asymmetric septal hypertrophy leading to LV diastolic dysfunction. Subsequently, patients with HCM exhibit exaggerated or hyper-contractile systolic function. Often, 
asymmetric septal hypertrophy seen in HCM may obstruct the aorta. Elevated enddiastolic pressures are also often measured in these patients. Arrhythmias and mitral valve regurgitation are also associated with HCM.

\subsubsection{Restrictive Cardiomyopathy}

Restrictive cardiomyopathy is the rarest form of cardiomyopathy with the poorest prognosis (22). It is often caused by diseases such as endocardial fibrosis or other disease conditions that result in myocardial stiffening. Restrictive cardiomyopathy has also been shown to follow autosomal dominant or autosomal recessive patterns of inheritance (21). Patients with restrictive cardiomyopathy have a stiff LV wherein diastolic dysfunction limits ventricular filling (21). Asymptomatic diabetics commonly suffer from this type of cardiomyopathy (28). Obliterative cardiomyopathy, often referred to as severe restrictive cardiomyopathy, occurs when diastolic filling is completely restricted.

\subsubsection{Diabetic Cardiomyopathy}

Diabetes mellitus is frequently known to affect heart muscle and is acknowledged to be the cause of a specific type of cardiomyopathy without significant coronary artery disease or hypertension (28). Older patients with diabetes frequently exhibit signs of diastolic dysfunction without other symptoms (29). However, in the presence of a myocardial infarction or ischemia, diabetic cardiomyopathy may become severe (29). Systolic dysfunction and hypertrophy are also associated with diabetic cardiomyopathy (28). Diastolic dysfunction expressed as impaired ventricular filling is also very common in diabetic 
cardiomyopathy, which has been attributed to reduced end-diastolic volume. Stiffness of the ventricle has been associated with mild or moderate obesity which occurs in diabetics. Diastolic dysfunction is likely due in part to fibrosis, a common characteristic of diabetic cardiomyopathy (30).

\subsubsection{Valvular Heart Disease}

Valvular heart disease may present itself in many forms. All types of valvular heart disease place excess hemodynamic stress on either the left of right ventricle for which the heart must compensate (31). Therefore, most valvular diseases lead to the onset of cardiac hypertrophy and may result in congestive heart failure (32). Over the past 15 years, non-invasive monitoring, improvement of prosthetic valves, better valvular reconstruction techniques and timing of surgical intervention have led to improvements in the outcome of patients with valvular disease (32).

Valvular insufficiencies fall into two categories: those that regurgitate and those that are stenotic. Regurgitation may be caused by a congenital defect (33), by diseases such as endocarditis (32) or with aging (34). The consequence of a regurgitant valve is that it does not seal properly; blood leaks back into the chamber from which it came and leads to VO. Stenosis, on the other hand, is defined as a narrowing of a valvular opening that restricts the amount of blood able to travel through it. The causes of stenotic valves may be congenital (35), calcific-degenerative (34), or due to rheumatic disease (32). The resultant narrowing of the valvular opening increases the demand for the heart to pump 
blood through to the body at a higher pressure to meet the demands of the tissue and organs. This increased demand leads to PO.

\subsubsection{Mitral Valve Regurgitation}

Mitral valve regurgitation is a disease caused by endocarditis, myxomatous degeneration of the mitral valve, collagen vascular disease, rupture of the chordae tendinae or rheumatic fever (32), and results in a fraction of systolic blood being pumped from the LV to backup into the left atrium. Initially, acute mitral valve regurgitation leads to $\mathrm{VO}$ of the $\mathrm{LV}$, and thus to the formation of eccentric hypertrophy (36) (See section 2.9), to compensate for the insufficiency. Eventually, chronic regurgitation leads to heart failure once the pumping mechanism of the heart becomes compromised. In terms of cardiac function, patients with acute mitral regurgitation exhibit an increase in preload sarcomere length, causing an increase in end-diastolic volume. This results in an increased left ventricular ejection fraction (EF); however, nearly half of the volume of blood ejected is being regurgitated into the left atrium, while the remaining $50 \%$ is sent as forward stroke volume. Thus, despite an increase in EF, stroke volume is reduced. Later, when the heart is in a chronic compensated state, end-diastolic volume increases so much so that despite a $50 \%$ regurgitation rate, stroke volume returns to normal. Once the heart can no longer compensate and the contractile function of the heart starts to decline, EF and forward stroke volume both decline causing a larger percentage of blood to be regurgitated into the left atrium. The end result is backward failure (See section 2.4.5) which leads to pulmonary 
congestion and right ventricular dysfunction (32). Well-timed mitral valve repair or replacement surgery is common today and often results in good prognoses for patients (36).

\subsubsection{Aortic Valve Regurgitation}

Similar to mitral regurgitation, aortic regurgitation may be caused by diseases such as endocarditis or rheumatic fever that affect the aortic leaflets. Other causes of aortic regurgitation include diseases to the aortic root such as aortoannular ectasia (dilatation of the ascending aorta and aortic annulus), Marfan's syndrome (defective connective tissue fibrillin gene), collagen vascular disease, aortic dissection (tear in the aortic lining) and syphilis (32). Regurgitant aortic valves lead to an increase in LV end-systolic blood volume (dilatation), resulting in chronic VO and eccentric hypertrophy of the $\operatorname{LV}(37,38)$. This causes an increase in stroke volume due to a large total stroke volume which is ejected into the aorta. In addition to VO, aortic regurgitation causes an increased afterload resulting in systolic hypertension. Therefore PO, and thus concentric hypertrophy (See section 2.8), is also present. Symptoms of aortic regurgitation often do not appear until LV dysfunction begins, long after the onset of the regurgitant valve. Symptoms include those of left-sided heart failure (See section 2.4.4) as well as angina, which is less frequent. Surgical intervention is often required in patients with aortic regurgitation, and is recommended to occur before EF is reduced below 55\%. To delay surgeries to repair or replace aortic valves, drugs such as 
nifedipine may be used to improve LV performance and to reduce aortic regurgitation (32).

\subsubsection{Tricuspid Valve Regurgitation}

Tricuspid regurgitation is often secondary to mitral or aortic valve insufficiencies and is therefore a symptom of late stage valvular failure. It is visible by echocardiography in almost two thirds of patients who have undergone mitral valve repair (39). Patients with elevated right ventricular systolic pressure often suffer from tricuspid regurgitation (40).

\subsubsection{Mitral Valve Stenosis}

Most cases of mitral valve stenosis occur in women who suffer from rheumatic fever. Despite a decrease in the incidence of both rheumatic heart disease and mitral stenosis in the developed world, both are still common in the developing world (32). Symptoms of left-sided heart failure (See section 2.4.4) and backward failure of the LV (See section 2.4.5) are characteristic of this disease. Due to the narrowing of the mitral valve, mitral stenosis induces a pressure build-up in the left atrium and reduces LV filling causing a decrease in $\mathrm{CO}(32)$.

\subsubsection{Aortic Valve Stenosis}

Aortic stenosis, which results from the degeneration and calcification of the aortic leaflets, is usually of idiopathic origin (32). Symptoms of aortic stenosis include angina, syncope and symptoms of CHF. A stenotic aortic valve causes a build-up of pressure in the LV resulting in concentric hypertrophy 
(See section 2.8) and increased collagen deposition. This hypertrophy results in diastolic dysfunction. Systolic dysfunction may also occur due to excess afterload and decreased contractility (32).

\subsubsection{Congenital Heart Diseases}

There are many types of congenital defects of the heart, including those that affect the mitral valve, tricuspid valve and aortic valve. Other common congenital defects include ventricular septal defects, atrial septal defects and patent ductus arteriosus. Often congenital abnormalities repair themselves over time, but some do not and thus require surgical intervention.

\subsection{Physiological Aspects of Heart Failure}

The physiology of heart failure is complex and may be classified in many different ways. The following are 5 different approaches to categorize heart failure; however, it is understood that none may exist without the other. Also, it is possible for combinations of these types of heart failure to co-exist.

\subsubsection{Systolic Versus Diastolic Failure}

While systolic heart failure is defined as the inability of the LV to expel sufficient blood, diastolic failure is explained by the inability of LV to fill normally. However, there is a strong association between diastolic and systolic failures, as without normal filling of the LV there will not be a sufficient amount of blood to expel. Reduced $\mathrm{CO}$ is a sign of systolic failure which causes reduced tissue perfusion and thus fatigue, weakness and exercise intolerance. In diastolic failure, there can be an increase in resistance to the inflow of blood to the $\mathrm{LV}$, or a 
reduction in ventricular capacity (14). Characteristics of systolic dysfunction include low EF, while diastolic dysfunction is often characterized by normal ejection with impaired myocardial relaxation and diminished early diastolic filling (17).

\subsubsection{High Output Versus Low Output Failure}

Models of low $\mathrm{CO}$ are secondary to factors such as ischemic heart disease, hypertension, dilated cardiomyopathy, and valvular and pericardial disease. High output models include secondary responses to factors such as hyperthyroidism, anemia, pregnancy, arteriovenous fistulas, beriberi, and Paget's disease (14). Usually, heart failure due to PO leads to relatively low output failure, while heart failure due to VO leads to high output failure.

\subsubsection{Acute Versus Chronic Failure}

Acute heart failure occurs suddenly in patients who suffer a myocardial infarction or a valvular rupture. Often, acute heart failure results in systolic failure, including reduced $\mathrm{CO}$ and hypotension. Conversely, chronic heart failure develops and progresses over a period of time, as is the case in dilated cardiomyopathy as well as clinical and laboratory models of PO and VO. Peripheral edema is often a symptom of chronic failure (14).

\subsubsection{Right-Sided Versus Left-Sided Failure}

Left-sided heart failure, and more specifically LV failure, is the more common of these two types of failure. Right-sided failure only occurs in patients with congenital defects to the right side of the heart or in patients with pulmonary 
disease (14). Almost all other causes of heart failure lead to left-sided heart failure. Symptoms of left-sided failure include dyspnea (17), othopnea and paroxysmal nocturnal dyspnea (32).

\subsubsection{Forward Versus Backward Failure}

Forward failure, exemplified in aortic stenosis or DCM, occurs when an obstruction inhibits ejection of blood from the LV or when damage to the myocardium reduces systolic shortening. Mitral stenosis is an example of backward failure wherein venous return to the LV is limited due to narrowing of the valve. HCM also causes backward failure of the $\mathrm{LV}$, as concentric $\mathrm{LV}$ hypertrophy limits the volume of ventricular filling. Katz (14) notes that backward and forward failures co-exist, as reduced filling limits ejection while reduced ejection disrupts normal filling.

\subsection{Biophysics and Biochemistry of Heart Failure}

When the heart is subjected to hypertrophy (See sections $2.7-2.11$ ) or is undergoing failure, it becomes starved of energy, specifically due to a lack of oxygen. This lack of oxygen leads to ischemia and may be due to alterations in the size of cardiac myocytes, which cause reduced perfusion of oxygen to tissues, and/or due to decreased capillary density and intercapillary space. The resulting alterations in cellular metabolism lead to an overall reduction in the level of highenergy phosphates like adenosine triphosphate (ATP) and creatine phosphate (14).

Not only can anatomical alterations cause impairment of cellular metabolism, but so to can altered biochemical pathways. Altered gene regulation 
in the failing heart limits energy production by reducing levels of enzymes such as creatine phosphokinase and those that oxidize fatty acids. The failing heart also exhibits abnormalities in structures involved in excitation-contraction coupling, which are caused by alterations in gene expression. However, little is known about the connection between impaired pump function and the underlying cellular pathways leading to changes in gene expression (14).

\subsubsection{Oxidative Stress in Heart Failure}

Oxidative stress is thought to play a crucial role in the pathogenesis of heart failure (41); however, the correlation between oxidative stress and the clinical parameters of heart failure remain unclear (42). In the normal heart there is a balance between reactive oxygen species (ROS) and antioxidants; however, oxidative stress occurs when the balance shifts toward an increase in ROS and a reduction in antioxidants. Major ROS include the superoxide anion $\left(\mathrm{O}_{2}{ }^{-{ }^{-}}\right)$, hydroxyl radical $\left({ }^{\circ} \mathrm{OH}\right)$ and hydrogen peroxide $\left(\mathrm{H}_{2} \mathrm{O}_{2}\right)$, whose harmful effects have been studied for over 50 years (43). Nitric oxide radical (NO) and peroxynitrite $\left(\mathrm{ONOO}^{-}\right)$, which is derived from $\mathrm{NO}$, are also forms of ROS. Whereas $\mathrm{O}_{2}{ }^{-}$is a normal byproduct of oxidative phosphorylation (44), $\mathrm{NO}^{\circ}$ is an enzymatic product of the vascular endothelium through the L-arginine pathway (45). As the cardiovascular system is a major target for ROS which may cause severe damage to myocytes (45), understanding the effects of oxidative stress in heart failure is of significant importance. 
Experiments using abdominal aortic banding as a model of PO in rats have shown that concentric hypertrophy leads to increased antioxidant levels which are responsible for: maintaining cardiac function in response to free radicals, better recovery after ischemia/reperfusion and reduced incidence of arrhythmias (41). These increased levels were due to an increase in the production of antioxidant enzymes such as superoxide dismutase (SOD) and glutathione peroxidase (GPx), which are responsible for the breakdown of ROS.

In the failing heart, the opposite change occurs; there is a shift toward increased ROS and a decrease in antioxidants. Dhalla and Singal (46) showed decreased levels of myocardial SOD and GPx in chronically failing guinea pig hearts subjected to ascending aortic banding. Dhalla et al. (47) points to oxidative stress as the initiating step from hypertrophy to heart failure, while other studies have made the link between chronic ROS production and the development of hypertrophy and the progression of heart (48). A recent study on mice subjected to VO via arteriovenous fistula has shown that they exhibit signs of oxidative stress which may be abolished by administering matrix metalloproteinase inhibitors (49).

Oxidative stress may also have a profound effect on calcium $\left(\mathrm{Ca}^{2+}\right)$ handling at the level of the cardiomyocyte (45). Studies have shown that $\mathrm{Ca}^{2+}$ handling across the sarcolemma and the sarcoplasmic reticulum (SR) may be altered due to oxidative stress when the heart is subjected to failure $(50,51,52)$. 


\subsection{Alterations in Calcium Handling in Heart Failure}

$\mathrm{Ca}^{2+}$ plays a major role in a variety of intracellular signalling pathways including muscle contraction. Within the cardiomyocyte, $\mathrm{Ca}^{2+}$ influx and efflux across the sarcolemma and the SR is required for sarcomeric contraction and relaxation (53). When a myocyte depolarizes, $\mathrm{Ca}^{2+}$ is able to enter the cell via $\mathrm{L}$ type voltage-dependent (dihydropyridine sensitive) $\mathrm{Ca}^{2+}$ channels (DHPR). This influx of $\mathrm{Ca}^{2+}$ triggers a much larger release of the $\mathrm{Ca}^{2+}$ from the SR, the major $\mathrm{Ca}^{2+}$ storage organelle, into the cytosol via the ryanodine receptor (RyR2). This process is called $\mathrm{Ca}^{2+}$-induced $\mathrm{Ca}^{2+}$ release (54), and is required for cardiac contraction. To initiate relaxation, cytosolic $\mathrm{Ca}^{2+}$ is returned to the SR though the sarco/endoplasmic reticulum $\mathrm{Ca}^{2+}$-ATPase (SERCA2a) which is regulated by the inhibitory protein phospholamban (PLB). A smaller percentage of extraneous cytosolic $\mathrm{Ca}^{2+}$ is removed from the myocyte though the $\mathrm{Na}^{+} / \mathrm{Ca}^{2+}$ exchanger (NCX) (53).

Key sarcolemmal proteins such as DHPR and NCX play an important role in the pathogenesis of heart failure. A recent study has shown that cardiac NCX activity decreases in spontaneously hypertensive rat hearts in order to maintain high $\mathrm{Ca}^{2+}$ levels for sufficient contraction in the presence of increased afterload (55). Another study demonstrates that the expression of cardiac NCX is activated upon adrenergic stimulation, which has been shown to induce hypertrophy (56). DHPR has also been implicated in cardiac contractile dysfunction. A new study demonstrates the possibility that, in hibernated myocardium (due to reversible 
coronary stenosis), a decrease in $\mathrm{SR} \mathrm{Ca}^{2+}$ release could be linked to decreased $\mathrm{Ca}^{2+}$ currents through DHPR (57). Benitah et al. (58) discuss the link between inefficient $\mathrm{Ca}^{2+}$ current through DHPR and reduced $\mathrm{Ca}^{2+}$ release, suggesting a reorganization of the t-tubules system in failing cells.

The SR plays a vital role in the pathogenesis of heart failure. Over the years, numerous experiments have linked alterations in SR protein expression to the progression of hypertrophy and heart failure. Specifically, critical proteins responsible for $\mathrm{Ca}^{2+}$ movement and thus cardiomyocyte contraction and relaxation - SERCA2a, PLB, and RyR2 - have been studied extensively (59-61). Cardiac contractile dysfunction has been linked to decreased expression and/or activity of SERCA2a and increased PLB to SERCA2a ratios (60). Reductions in myocardial contractility have also been linked to RyR2 hyperphosphorylation (62).

\section{Hypertrophy}

\subsection{Hypertrophy Defined}

Cardiac hypertrophy is defined by Katz (14) as an enlargement of the heart due to an increase in cell size without an increase in cell number (hyperplasia). When referring to the heart, the dogma that still holds today is that soon after birth the heart is terminally differentiated and may no longer increase in cell number. Thus, an enlargement of the heart is a purely hypertrophic response. As described above, there are many stimuli that may induce hypertrophy, including increased pressure, increased volume, or a combination of the two. However, the type of 
hypertrophy that the heart exhibits as a result of these two distinct stimuli is distinctly different.

\subsection{Pressure Overload Hypertrophy}

When the heart is subjected to a mechanical stimulus that causes excess pressure on the ventricular walls, the heart responds with a specific hypertrophic response. Such stimuli may be due to hypertension, valvular stenosis or HCM. In response, the myocardium attempts to counter the increase in pressure by reducing the excess amount of stress put on the ventricular walls. To do so, the myocardium must thicken, which is achieved by sarcomeric replication in parallel. This phenomenon, termed concentric hypertrophy, is thought to occur as result of increased protein synthesis within the cardiomyocyte (7). As a result, the biomechanical tension that was being placed on the walls of the heart due to PO is reduced via a compensatory hypertrophic mechanism.

\subsection{Volume Overload Hypertrophy}

When the heart is overloaded with excess blood volume, the heart must compensate accordingly. Diseases such as DCM, mitral valve regurgitation, anemia and congenital defects may all lead to VO wherein the ventricle must increase its ability to pump out an excess volume of blood present due to some mechanical stimulus. As a result, the heart hypertrophies by increasing cell length via sarcomeric replication in series - eccentric hypertrophy. Such a mechanism allows the ventricle to increase stroke volume to compensate for that which is lost due to the stimulus. In the case of aortocaval shunt, eccentric hypertrophy allows 
for the heart to compensate for excess venous return while supplying the rest of the body with sufficient blood, while in mitral regurgitation eccentric hypertrophy allows for an increase in total stroke volume to make up for the stroke volume that is lost due to backflow to the left atrium.

\subsection{Adaptive (Physiological) Versus Maladaptive (Pathological) Left Ventricular Remodelling}

When a heart undergoes hypertrophic remodelling due to PO or VO, it makes the required changes to overcome the stimulus. However, are these changes adaptive or maladaptive? Are they reversible or irreversible? Gaining the answers to these questions is fundamental to understanding the hypertrophic processes and treating disease states.

As hypertrophy initially compensates for a negative stimulus, it is thought to be a beneficial adaptive response. However, chronic hypertrophy is associated with increased morbidity and mortality, and thus is maladaptive (63). The main difference between physiological and pathological hypertrophy is that, in pathological states, the hypertrophic adaptations of the LV are either unable to meet the increased demands of the heart or that the adaptations made by the heart compromise normal cardiac function (63). Remodelling is also considered to be maladaptive when hypertrophy does not regress once the negative stimulus is removed. Conversely, adaptive physiological hypertrophy, which is often seen in athletes, regresses upon cessation of exercise (64). 
The differences between pathological and physiological hypertrophy may be witnessed at the cellular level. In the case of concentric hypertrophy, both adaptive and maladaptive responses to stimuli include the parallel addition of new sarcomeres. However, pathological states such as aortic stenosis may include necrosis and increased fibrosis of the myocardium. This may lead to diastolic dysfunction, ventricular stiffness and reduced contractile function without the possibility of regression. In adaptive models of concentric hypertrophy like weight training, similar structural changes occur at the level of the sarcomeres; however, this is accompanied by increased capillary density. The resulting changes lead to normal or even enhanced contractile function and efficiency, while the possibility for regression of hypertrophy remains upon removal of the stimulus.

In $\mathrm{VO}$, there are similar cellular distinctions between adaptive and maladaptive hypertrophic responses. Both pathological and physiological states of VO demand the addition of new sarcomeres in series to counteract the stimulus in place. However, pathological hypertrophy in cases such as mitral valve stenosis may include both myocyte necrosis and thinning of the ventricular walls. This is often associated with reduced systolic function due to myocyte slippage. In physiological models of $\mathrm{VO}$ there is no necrosis and both contractile function and cardiac efficiency remain normal or enhanced. In physiological states of VO such as marathon training, the potential for regression of hypertrophy exists upon cessation of exercise, while pathological eccentric hypertrophy is irreversible. 


\subsection{Experimental Models of Pressure \& Volume Overload-Induced Failure}

There are many different experimental models available to study PO or VO in animals. Rats, mice, rabbits, dog, cats and pigs are commonly used for in these types of experiments, as they are useful models of mimicking clinically relevant pathologies.

\subsubsection{Pressure Overload}

The following methods are used to induce PO in animals, often resulting in different degrees of PO between and within models.

\subsubsection{Abdominal Aortic Banding}

The most common type of banding technique is the aortic banding model which may be performed at many anatomical regions including the suprarenal aorta. Abdominal aortic banding in rats is a common invasive experimental model of PO (65-67).

\subsubsection{Transverse Aortic Constriction}

Transverse aortic constriction (TAC) is less invasive than suprarenal abdominal aortic banding but requires fine microsurgical techniques (68). It involves the constriction of the aorta at the level of the aortic arch, which is much closer to the heart than abdominal aortic banding. In this regard, TAC may induce a greater degree of pressure on the LV than abdominal aortic banding. However, TAC produces variable degrees of cardiac hypertrophy (69). 


\subsubsection{Other Animal Models of Pressure Overload}

Other methods of inducing PO occur at the level of the lungs. Pulmonary constriction is used in larger animals such as dogs and induces hypertrophy of the right ventricle (70).

\subsubsection{Volume Overload}

The following methods are used to induce VO in animals, often resulting in different degrees of VO between and within models.

\subsubsection{Mitral Valve Regurgitation}

Animal models of mitral valve regurgitation can be created by surgical catheterization to the left atrium followed by cutting the chordae tendineae. (71).

\subsubsection{Tricuspid Valve Regurgitation}

Animal models of tricuspid valve regurgitation are useful for mimicking right ventricular overload. Surgical procedure involves cutting the chordae tendineae (72).

\subsubsection{Aortic Valve Regurgitation}

To surgically induce aortic valve regurgitation in animal models, catheterization is performed at the level of the right carotid artery and is advanced through the aorta and into an aortic leaflet until it is ruptured $(38,73)$. The experiments are often performed under echocardiographic guidance $(38,74)$. 


\subsubsection{Anemia}

Animal models of anemia may be used to create VO while avoiding surgical intervention. Restricting dietary iron in young animals combined with bleeding induces this condition.

\subsubsection{Arteriovenous Shunt (Fistula)}

The most common type of arteriovenous shunt used in experimental models is the aortocaval shunt (75-76), which has been performed on rats, dogs, cats and pigs. An aortocaval shunt is created by puncturing the abdominal aorta through to the vena cava, forming a short loop within the systemic blood circulation. A less common type of shunt is the aortopulmonary (77).

\section{$\underline{\text { Echocardiography }}$}

\subsection{Echocardiography: General Overview}

Echocardiography is a versatile, well-established and widely used diagnostic tool that may be used to assess cardiac structure and function in both human and veterinary medicine (78). Most importantly, it is a non-invasive, painless and in vivo procedure that allows for serial analyses of the same subject over a given period of time. As the resolution capabilities of this technology have increased, echocardiography has become a useful and indispensable tool for cardiac analysis in humans (79-81) and animals as small as rats $(38,74,82-88)$ or mice $(89,90)$

Echocardiography in its modern form has a multitude of uses that include acute and long term management of heart failure patients by monitoring the 
progression of regurgitant, stenotic or prosthetic valves, evaluating developing cardiomyopathies, hypertension, the condition of major blood vessels and the function of infarcted tissue. Prenatal ultrasound and fetal echocardiography can accurately detect $93 \%$ of congenital heart defects (91). Surgeons also use ultrasound, specifically echocardiography, as an indispensable tool to be able to monitor and guide surgical procedures $(38,74)$. Today, the applications for ultrasound are expanding from purely diagnostic toward both diagnostic and therapeutic. Therapeutic uses for ultrasound include aiding in the delivery of gene therapeutic molecules to specific target tissues (92) as well as having clot busting properties that help dissolve thrombi in patients with acute stroke $(93,94)$.

\subsection{Echocardiography and Hypertrophy}

In cases of hypertrophy, echocardiography is especially useful. Often, changes in cardiac structure and function in hypertrophy and/or early stage heart failure may be asymptomatic. As well, the often slow onset and progression of hypertrophy makes it easy to overlook in its initial stages. Therefore, early echocardiographic detection may be critical in managing, delaying or preventing the onset of heart failure. With the use of serial echocardiographic measurements, even slight alterations in structure and/or function can be visualized.

In hypertrophy due to PO or VO, echocardiography is useful in determining both cardiac structure and function. In terms of structure, measurements of wall thickness and chamber dimensions may be used to determine which type of hypertrophy is occurring, while measurements of left ventricular mass (LVm) may 
be used as general indicator of hypertrophy. Parameters of systolic function may also be determined echocardiographically and are mostly calculated using structural data. These data are useful for assessing alterations in the contractile function of the heart. Parameters of diastolic function may also be calculated using Pulse Wave Doppler imaging, and may be useful for detecting changes in ventricular filling or relaxation.

\subsubsection{Echocardiography in Pressure Overload}

Echocardiography is useful for detecting alterations in cardiac structure and function due to PO (95). Furthermore, diastolic dysfunction in LV hypertrophy due to PO stimuli has been shown echocardiographically for decades. For example, Shapiro and Gibson (96) showed that PO in humans induces prolonged IVRt and reduced diastolic filling velocities. More modern echocardiographic studies in animals have demonstrated its versatility. Numerous studies of PO have assessed diastolic and systolic function, LVm and chamber dimensions (82, 86, 88, 97, 98). Regression of PO is also detectable using echocardiography (100). This is useful in clinical situations wherein the status of patients with aortic valve replacements can be monitored (101).

\subsubsection{Echocardiography in Volume Overload}

Echocardiography is equally valuable for diagnosing and monitoring the progression of a wide range of VO-induced hypertrophies including mitral regurgitation (32), tricuspid regurgitation (39) and aortic regurgitation $(38,73)$. Studies have shown that severe aortic regurgitation in rats induces increased LVm, 
increased LV chamber dimensions and systolic dysfunction measured as a decreased percentage of left ventricular fractional shortening (FS) $(38,73)$. 


\section{STATEMENT OF HYPOTHESIS}

Despite a number of previous studies that have assessed echocardiographic parameters in PO- and VO-induced hypertrophy, there have been no studies to date that have performed an elaborate, serial echocardiographic characterization of heart structure and function from the onset of hypertrophy to decompensatory heart failure. Furthermore, there have been no studies that present a comparative echocardiographic analysis of cardiac structure and function comparing the differential changes that occur between different models.

We hypothesize that PO and VO will induce differential cardiac remodelling that will manifest as unique echocardiographic parameters. Cardiac remodelling will be associated with cardiac contractile dysfunction, although at different time points and through different mechanisms. In VO, systolic dysfunction will be prominent, while in PO systolic and diastolic dysfunction will be evident. Also, general characteristics of PO and VO rats will show the presence of cardiac hypertrophy and early signs of failure such as organ congestion and/or ascites. 


\section{MATERIALS AND METHODS}

The following experimental protocols were approved by the Animal Care Committee of the University of Manitoba and are in agreement with the Canadian Council on Animal Care Concerning the Care and Use of Experimental Animals (Vol. 1, 2 ${ }^{\text {nd }}$ Edition, 1993).

\subsection{Creation of the Animal Models}

Male Sprague-Dawley rats weighing $75-150 \mathrm{~g}$ were kept in a temperature and humidity-controlled room with a 12-hour light-12-hour dark cycle for one week prior to creation of the PO and VO models, respectively. Standard rat chow and tap water were available ad libitum. PO was induced via the abdominal aortic banding method, while VO was induced via the aortocaval shunt. All rats were anesthetized for surgery with $5 \%$ isoflurane carried by oxygen at a flow rate of $2 \mathrm{~L} / \mathrm{min}$. Rats were then maintained under a surgical plane of anesthesia with $2 \%$ isoflurane. For PO, a laparotomy was performed and the suprarenal abdominal aorta was exposed. A silk suture was used to tie off the vessel using a blunt 21gauge needle as a guide. Successful bands were snug while still maintaining blood flow to the kidneys and lower extremities. For VO, a laparotomy was performed and the abdominal aorta and vena cava were exposed by blunt dissection between the renal arteries and the iliac bifurcation. An 18-gauge needle was inserted into the exposed aorta at a $45^{\circ}$ angle and pushed through to the vena cava, creating the shunt. Cyanoacrylate (Krazy Glue, Elmer's Product Canada, Toronto, ON) was used to seal the puncture. In successful VO rats, oxygenated blood from the 
abdominal aorta could be seen mixing in the vena cava with deoxygenated venous blood. Sham operated animals served as controls for both groups and were subjected to the same surgeries except for the creation of the band or the shunt. Rat housing conditions, as described above, remained constant throughout the duration of the 28-week experiment.

\subsection{General Characteristics}

Rats from both models were weighed and anesthetized using a cocktail of ketamine $(90 \mathrm{mg} / \mathrm{kg})$ and xylazine.(10 mg/kg) prior to sacrifice. Hearts were removed, washed in ice-cold saline and total heart weights were measured. Lungs and liver were removed, washed in ice-cold saline and wet weights were recorded. Lungs and liver were then set to dry and weighed again.

\subsection{Echocardiography}

Rats were weighed and anesthetized using isoflurane as described previously. Two-dimensionally (2D)-guided M-mode echocardiography and Pulse Wave Doppler echocardiography were performed using a Sonos 5500 ultrasound system (Agilent Technologies, Andover, MA) equipped with a $12 \mathrm{MHz}$ (s12) transducer. For M-mode recordings, the parasternal short-axis view was used to image the heart in $2 \mathrm{D}$ at the level of the papillary muscles with a depth setting of 3 $\mathrm{cm}$. M-mode recordings were then analyzed at a sweep speed of $150 \mathrm{~mm} / \mathrm{s}$ with the axis of the probe aligned with the middle of the ventricle. The following parameters were measured using the leading edge methods described by the American Society of Echocardiography (102): FS, EF, CO, LVm, heart rate (HR), 
left ventricular internal dimensions at both diastole and systole (LVIDd and LVIDs, respectively), left ventricular posterior wall dimensions at both diastole and systole (LVPWd and LVPWs, respectively) and interventricular septal dimensions at both diastole and systole (IVSd and IVSs, respectively). CO was obtained echocardiographically and derived from the following formula:

$$
\begin{gathered}
\mathrm{CO}=((\mathrm{EDV}-\mathrm{ESV}) / 1000) * \mathrm{HR} \\
\text { where } \mathrm{EDV}=\mathrm{LVIDd}^{3} \text { and } \mathrm{ESV}=\mathrm{LVIDs}^{3}
\end{gathered}
$$

LVm was also obtained echocardiographically and derived via the cubic equation at end diastole:

$$
\mathrm{LVm}=0.8(1.4)\left(\left(\mathrm{IVSd}+\mathrm{LVIDd}+\mathrm{LVPWd}^{3}-\mathrm{LVIDd}^{3}\right)+0.6\right.
$$

Stroke volume (SV) was calculated as:

$$
\mathrm{SV}=\mathrm{EDV}-\mathrm{ESV}
$$

The following Doppler measurements were taken using the apical 4chamber view: peak early diastolic filling velocity (E wave), peak late diastolic filling velocity (A wave), E/A ratio and $\mathrm{E}$ deceleration time (E decel time). The apical 5-chamber view was used to assess aortic ejection time (AEt) as well as IVRt, which is the time from aortic valve closure to the onset of mitral flow. Values obtained for statistical analysis were average data collected from three cardiac cycles. Some studies were recorded onto standard VHS tapes while others were recorded onto a magneto-optical disk for offline analysis. Photographs were taken of data stored on the magneto-optical disk using a 4 Megapixel digital camera. 


\subsection{Experimental Protocol}

Both experimental groups (PO and $\mathrm{VO}$ ) were assessed for heart function by M-mode echocardiography at $1,2,4,8,16$ and 28 weeks post-surgery, while Doppler measurements were taken at 2, 4, 8, 16 and 28 weeks post-surgery. At each time interval, random rats from both control and experimental groups were selected for analysis of general characteristics by the aforementioned techniques.

\subsection{Statistical Analysis}

Values are expressed as mean \pm standard error. One way analysis of variance (ANOVA) was used to analyze variations between the means of groups. Significant values versus sham controls are defined as $\mathrm{P}<0.05$. 


\section{RESULTS}

\subsection{General Characteristics}

The heart-to-body weight (HBW) ratio is a general marker for cardiac hypertrophy. As seen in Tables 1 and 2, the HBW ratio in both PO and VO models significantly increased as early as 2 weeks and remained elevated compared to sham controls throughout each time course. The same trend was observed with wet heart weights in both models as well. Neither the PO nor the VO model exhibited significant differences in body weights compared to their respective sham controls, expect for the 28-week end point in the VO model, which showed significantly elevated body weight.

The organ wet-to-dry weight ratio determines whether or not there is congestion, while ascites, fluid build-up in the abdominal cavity, is a sign of congestion and late-stage heart failure. Table 1 demonstrates that there was no congestion of the lungs at any time point in PO rats, while the liver experienced congestion at 28 weeks. Only a few PO rats at 28 weeks had significant fluid build up in the abdominal cavity. Table 2 shows that lung congestion occurred only at 28 weeks in VO rats, while no congestion of the liver was observed at any time point. VO rats displayed a few cases of ascites as early as 16 weeks. By 28 weeks, ascites was visible in half of the rats.

\subsection{Left Ventricular Mass}

LVm obtained by echocardiographic methods is widely accepted and commonly used as a marker for cardiac hypertrophy. In both PO and VO models 
we noticed a general overestimation of $L V m$ values obtained via echocardiography. These overestimations were determined upon collecting a large number of wet heart weights following animal sacrifice (as seen Tables 1 and 2) that were less than their corresponding echocardiographic LVm values (displayed in Figure 5). Therefore, a linear regression analysis was performed in order to determine the correlation between 28 -week LVm values and corresponding wet heart weights. $\mathrm{LVm}$ values were found to be highly correlated with wet heart weights in PO $(r=0.938)$ and in VO $(r=0.978)$ as demonstrated in Figure 5.

\subsection{Left Ventricular Dimensions}

In order to differentiate between concentric and eccentric hypertrophy, LV dimensions were analyzed for chamber dimensions and wall thicknesses. Typical M-mode echocardiograms are displayed in Figure 1. Figure 2 demonstrates the changes that occurred in the left ventricular internal dimension (LVID), IVS and LVPW at both diastole (Panels A, C, E) and systole (Panels B, D, F). From as early as 2 weeks post-surgery, LVID (Panels A and B) significantly increased in VO rats compared to controls. This trend continued to 28 weeks where VO rats exhibited chamber dilatation at diastole that reached $140 \%$ (156\% at systole) of sham values. Conversely, no significant changes in IVS (Panels C and D) or LVPW (Panels E and F) were found in VO rats with the exception of a slight but significant thickening of the LVPW at 28 weeks ( $110 \%$ of sham values at diastole and $105 \%$ of sham values at systole). PO rats exhibited significant thickening of the IVS at 2 weeks which progressed to reach $117 \%$ of control values at 28 weeks. 
Also, the LVPW underwent thickening in PO rats, but reached its maximum size by the 8-week time point in both sham and PO rats. In PO rats, LVPW was significantly increased at all time points at diastole and systole. Subsequently, PO rats exhibited no marked chamber dilatation; however, some time points showed statistically significant yet marginal increases in LVID.

\subsection{Systolic Function}

Figure 3 demonstrates the changes in FS and EF that occurred over the time course of changes in both $\mathrm{PO}$ and $\mathrm{VO}$ rats. In VO rats, reduced systolic function was first noted at 2 weeks with reduced FS and EF. Both of these trends continued throughout the time course. PO rats first displayed reduced systolic function at the 8-week time point, having both reduced FS and EF. These trends also continued throughout the remainder of the time course.

\subsection{Cardiac Output, Heart Rate and Stroke Volume}

In order to differentiate between high and low output failure, $\mathrm{CO}$ and cardiac index $(\mathrm{CI})$, a ratio of CO-to-body weight, were measured and displayed in Figure 4. In VO rats, both $\mathrm{CO}$ and $\mathrm{CI}$ increased significantly over time starting from as early as 2 weeks. By 28 weeks, CO and CI more than doubled (200\% and $219 \%$ of sham values, respectively). In PO rats, $\mathrm{CO}$ did not significantly increase until 8 weeks. Both $\mathrm{CO}$ and $\mathrm{CI}$ at 28 weeks were only slightly, but significantly elevated (117\% and $124 \%$ of sham values, respectively).

With respect to HR, there were no significant changes between control and experimental groups expect at the 28-week end point, where HR levels were 
elevated compared to controls in both PO and VO. As expected, stroke volume was significantly elevated throughout the VO time course, reaching $222 \%$ of sham values at 28 weeks. In PO rats, SV was significantly higher than controls at 8 and 16 weeks, however, this increase was relatively marginal $(117 \%$ and $120 \%$ of sham controls, respectively).

\subsection{Diastolic Function}

$\mathrm{E}$ wave, $\mathrm{A}$ wave and $\mathrm{E} / \mathrm{A}$ ratios were collected as markers for ventricular relaxation, compliance, and determination of diastolic function. VO rats exhibited significantly elevated $\mathrm{E}$ wave and $\mathrm{A}$ wave values compared with sham controls throughout the 28-week time course which resulted in an E/A ratio that continuously decreased over time. There were no significant changes in E decel time, IVRt or AEt. PO rats exhibited few changes in diastolic filling velocities until the 16-week time point when both $\mathrm{E}$ wave and $\mathrm{A}$ wave values became significantly elevated. PO rats then showed marked decreases in A wave velocities at the 28-week end point while maintaining an elevated $\mathrm{E}$ wave. The resulting $\mathrm{E} / \mathrm{A}$ ratio was sharply elevated at 28 weeks. There were no changes in $\mathrm{E}$ decel time. PO rats also exhibited significantly long IVRt and AEt, which are markers for impaired myocardial relaxation and impaired LV systolic function, respectively. 
Table 1. General characteristics of rats subjected to pressure overload (PO).

\begin{tabular}{|c|c|c|c|c|c|c|c|c|c|c|}
\hline & \multicolumn{2}{|c|}{2 weeks } & \multicolumn{2}{|c|}{4 weeks } & \multicolumn{2}{|c|}{8 weeks } & \multicolumn{2}{|c|}{16 weeks } & \multicolumn{2}{|c|}{28 weeks } \\
\hline Parameter & Sham & $\mathrm{PO}$ & Sham & $\mathrm{PO}$ & Sham & $\mathrm{PO}$ & Sham & $\mathrm{PO}$ & Sham & $\mathrm{PO}$ \\
\hline Heart Weight (g) & $\begin{array}{c}0.89 \pm \\
0.03\end{array}$ & $\begin{array}{l}1.08 \pm \\
0.08 *\end{array}$ & $\begin{array}{c}1.06 \pm \\
0.02\end{array}$ & $\begin{array}{l}1.55 \pm \\
0.06^{*}\end{array}$ & $\begin{array}{c}1.36 \pm \\
0.02\end{array}$ & $\begin{array}{l}1.77 \pm \\
0.05^{*}\end{array}$ & $\begin{array}{c}1.39 \pm \\
0.05\end{array}$ & $\begin{array}{l}2.00 \pm \\
0.06^{*}\end{array}$ & $\begin{array}{c}1.72 \pm \\
0.03\end{array}$ & $\begin{array}{l}2.31 \pm \\
0.09 *\end{array}$ \\
\hline $\begin{array}{c}\text { Body } \\
\text { Weight (g) }\end{array}$ & $\begin{array}{c}251.0 \pm \\
9.5\end{array}$ & $\begin{array}{c}243.8 \pm \\
5.6\end{array}$ & $\begin{array}{c}364.2 \pm \\
.4 .6\end{array}$ & $\begin{array}{c}348.4 \pm \\
5.7\end{array}$ & $\begin{array}{c}492.6 \pm \\
7.4\end{array}$ & $\begin{array}{c}506.5 \pm \\
8.3\end{array}$ & $\begin{array}{c}603.4 \pm \\
11.6\end{array}$ & $\begin{array}{c}606.2 \pm \\
14.6\end{array}$ & $\begin{array}{c}755.9 \pm \\
14.5\end{array}$ & $\begin{array}{c}742.8 \pm \\
15.6\end{array}$ \\
\hline $\begin{array}{l}\text { Heart Weight / } \\
\text { Body Weight } \\
\text { (mg/100g) }\end{array}$ & $\begin{array}{c}357.7 \pm \\
16.0\end{array}$ & $\begin{array}{c}446.2 \pm \\
38.4 *\end{array}$ & $\begin{array}{c}292.1 \pm \\
4.8\end{array}$ & $\begin{array}{c}447.0 \pm \\
18.7 *\end{array}$ & $\begin{array}{c}276.5 \pm \\
4.8\end{array}$ & $\begin{array}{c}350.8 \pm \\
10.8 *\end{array}$ & $\begin{array}{c}230.1 \pm \\
5.4\end{array}$ & $\begin{array}{c}330.7 \pm \\
10.8 *\end{array}$ & $\begin{array}{c}228.6 \pm \\
3.7\end{array}$ & $\begin{array}{c}310.3 \pm \\
9.3 *\end{array}$ \\
\hline Lungs Wet/Dry & $\begin{array}{l}4.75 \pm \\
0.05\end{array}$ & $\begin{array}{c}4.74 \pm \\
0.04\end{array}$ & $\begin{array}{c}4.28 \pm \\
0.34\end{array}$ & $\begin{array}{c}4.57 \pm \\
0.16\end{array}$ & $\begin{array}{c}4.42 \pm \\
0.09\end{array}$ & $\begin{array}{c}4.48 \pm \\
0.11\end{array}$ & $\begin{array}{c}3.81 \pm \\
0.05\end{array}$ & $\begin{array}{c}3.78 \pm \\
0.05\end{array}$ & $\begin{array}{c}3.93 \pm \\
0.19\end{array}$ & $\begin{array}{c}3.98 \pm \\
0.17\end{array}$ \\
\hline Liver Wet/Dry & $\begin{array}{c}3.25 \pm \\
0.03\end{array}$ & $\begin{array}{c}3.26 \pm \\
0.05\end{array}$ & $\begin{array}{c}2.61 \pm \\
0.02\end{array}$ & $\begin{array}{c}2.67 \pm \\
0.04\end{array}$ & $\begin{array}{c}2.90 \pm \\
0.01\end{array}$ & $\begin{array}{c}2.85 \pm \\
0.03\end{array}$ & $\begin{array}{c}2.80 \pm \\
0.01\end{array}$ & $\begin{array}{c}2.76 \pm \\
0.02\end{array}$ & $\begin{array}{c}2.81 \pm \\
0.02\end{array}$ & $\begin{array}{l}3.04 \pm \\
0.08 *\end{array}$ \\
\hline Ascites & - & - & - & - & - & - & - & - & - & + \\
\hline
\end{tabular}

$* \mathrm{P}<0.05$ vs. sham controls

$-=0,+=$ few,$++=$ half, $+++=$ most,$++++=$ all 
Table 2. General characteristics of rats subjected to volume overload (VO).

\begin{tabular}{|c|c|c|c|c|c|c|c|c|c|c|}
\hline & \multicolumn{2}{|c|}{2 weeks } & \multicolumn{2}{|c|}{4 weeks } & \multicolumn{2}{|c|}{8 weeks } & \multicolumn{2}{|c|}{16 weeks } & \multicolumn{2}{|c|}{28 weeks } \\
\hline Parameter & Sham & $\mathrm{VO}$ & Sham & VO & Sham & VO & Sham & VO & Sham & VO \\
\hline Heart Weight (g) & $\begin{array}{c}0.95 \pm \\
0.03\end{array}$ & $\begin{array}{l}1.47 \pm \\
0.09 *\end{array}$ & $\begin{array}{c}1.22 \pm \\
0.03\end{array}$ & $\begin{array}{l}1.87 \pm \\
0.15^{*}\end{array}$ & $\begin{array}{c}1.31 \pm \\
0.03\end{array}$ & $\begin{array}{l}1.98 \pm \\
0.13^{*}\end{array}$ & $\begin{array}{c}1.60 \pm \\
0.06\end{array}$ & $\begin{array}{l}2.67 \pm \\
0.09 *\end{array}$ & $\begin{array}{c}1.60 \pm \\
0.03\end{array}$ & $\begin{array}{l}3.19 \pm \\
0.17^{*}\end{array}$ \\
\hline $\begin{array}{c}\text { Body } \\
\text { Weight (g) }\end{array}$ & $\begin{array}{c}284.3 \pm \\
4.5\end{array}$ & $\begin{array}{c}283.3 \pm \\
6.4\end{array}$ & $\begin{array}{c}427.2 \pm \\
8.7\end{array}$ & $\begin{array}{c}424.6 \pm \\
12.5\end{array}$ & $\begin{array}{c}500.6 \pm \\
8.7\end{array}$ & $\begin{array}{c}521.5 \pm \\
8.2\end{array}$ & $\begin{array}{c}660.0 \pm \\
17.2\end{array}$ & $\begin{array}{c}666.8 \pm \\
10.4\end{array}$ & $\begin{array}{c}726.0 \pm \\
18.0\end{array}$ & $\begin{array}{c}799.0 \pm \\
20.0 \%\end{array}$ \\
\hline $\begin{array}{l}\text { Heart Weight / } \\
\text { Body Weight } \\
\text { (mg/lo0g) }\end{array}$ & $\begin{array}{c}333.0 \pm \\
9.29\end{array}$ & $\begin{array}{c}517.1 \pm \\
25.9 *\end{array}$ & $\begin{array}{c}285.2 \pm \\
7.11\end{array}$ & $\begin{array}{c}454.0 \pm \\
31.3^{*}\end{array}$ & $\begin{array}{c}262.5 \pm \\
6.15\end{array}$ & $\begin{array}{c}377.5 \pm \\
23.5^{*}\end{array}$ & $\begin{array}{c}229.6 \pm \\
5.19\end{array}$ & $\begin{array}{c}401.6 \pm \\
13.9 \%\end{array}$ & $\begin{array}{c}221.4 \pm \\
5.0\end{array}$ & $\begin{array}{c}408.5 \pm \\
21.1 *\end{array}$ \\
\hline Lungs Wet/Dry & $\begin{array}{c}4.84 \pm \\
0.21\end{array}$ & $\begin{array}{c}4.94 \pm \\
0.26\end{array}$ & $\begin{array}{c}4.51 \pm \\
0.11\end{array}$ & $\begin{array}{c}4.55 \pm \\
0.06\end{array}$ & $\begin{array}{c}4.18 \pm \\
0.12\end{array}$ & $\begin{array}{c}4.21 \pm \\
0.11\end{array}$ & $\begin{array}{c}4.04 \pm \\
0.22\end{array}$ & $\begin{array}{c}4.22 \pm \\
0.10\end{array}$ & $\begin{array}{c}4.11 \pm \\
0.04\end{array}$ & $\begin{array}{l}4.39 \pm \\
0.05^{*}\end{array}$ \\
\hline Liver Wet/Dry & $\begin{array}{c}3.06 \pm \\
0.13\end{array}$ & $\begin{array}{c}3.28 \pm \\
0.14\end{array}$ & $\begin{array}{c}3.03 \pm \\
0.06\end{array}$ & $\begin{array}{c}3.08 \pm \\
0.07\end{array}$ & $\begin{array}{c}2.83 \pm \\
0.04\end{array}$ & $\begin{array}{c}2.94 \pm \\
0.06\end{array}$ & $\begin{array}{c}2.77 \pm \\
0.02\end{array}$ & $\begin{array}{c}2.93 \pm \\
0.14\end{array}$ & $\begin{array}{c}2.86 \pm \\
0.02\end{array}$ & $\begin{array}{c}2.97 \pm \\
0.05\end{array}$ \\
\hline Ascites & - & - & - & - & - & - & - & + & - & ++ \\
\hline
\end{tabular}

$* \mathrm{P}<0.05$ vs. sham controls

$-=0,+=$ few,$++=$ half,$+++=$ most,$++++=$ all 

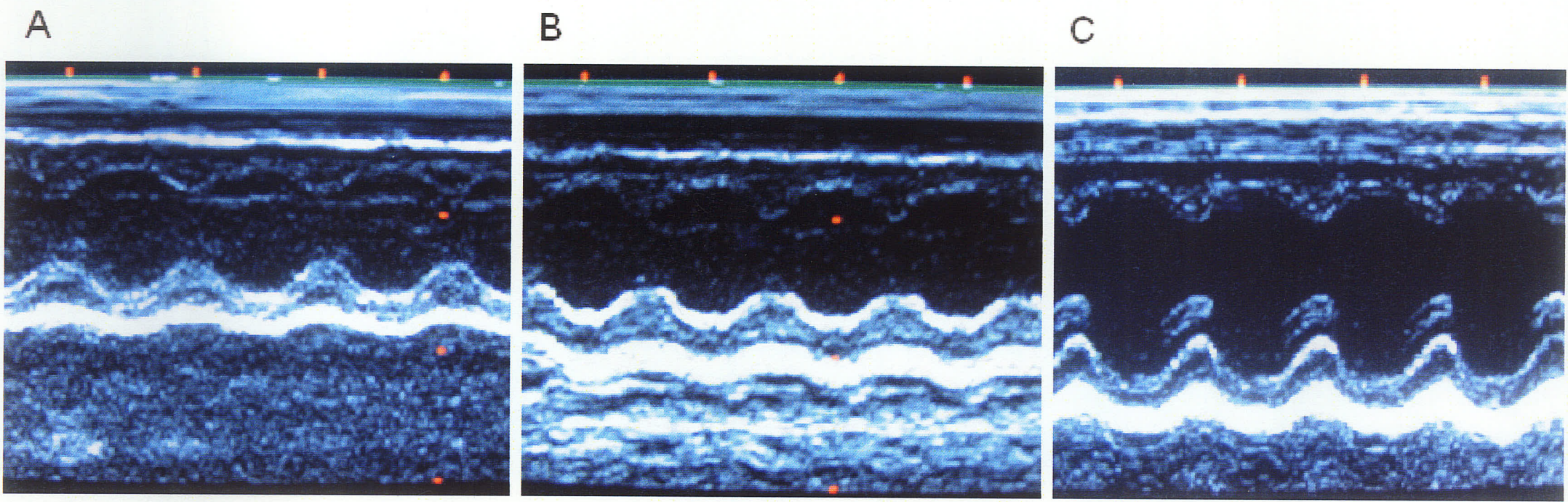

Figure 1. M-mode echocardiograms of representative left ventricles from sham (A), pressure overload (B) and volume overload $(\mathrm{C})$ rats at 28 weeks. 

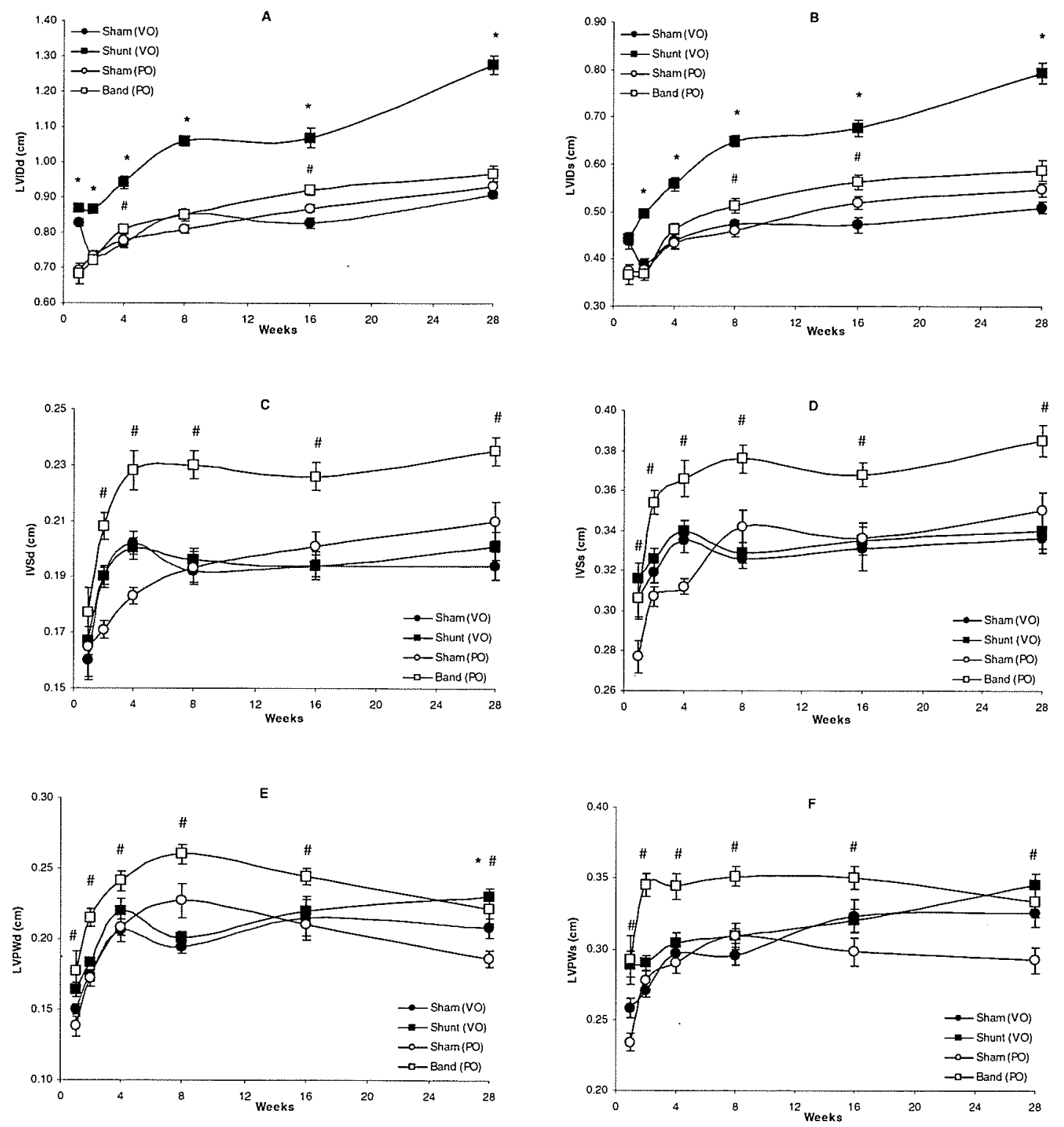

Figure 2. M-mode echocardiographic measurements of diastolic dimensions (A, C, E) and systolic dimensions $(\mathrm{B}, \mathrm{D}, \mathrm{F})$ in pressure overload $(\mathrm{PO})$ and volume overload (VO). \# $\mathrm{P}<0.05$ vs. sham (PO); ${ }^{*} \mathrm{P}<0.05$ vs. sham (VO). 

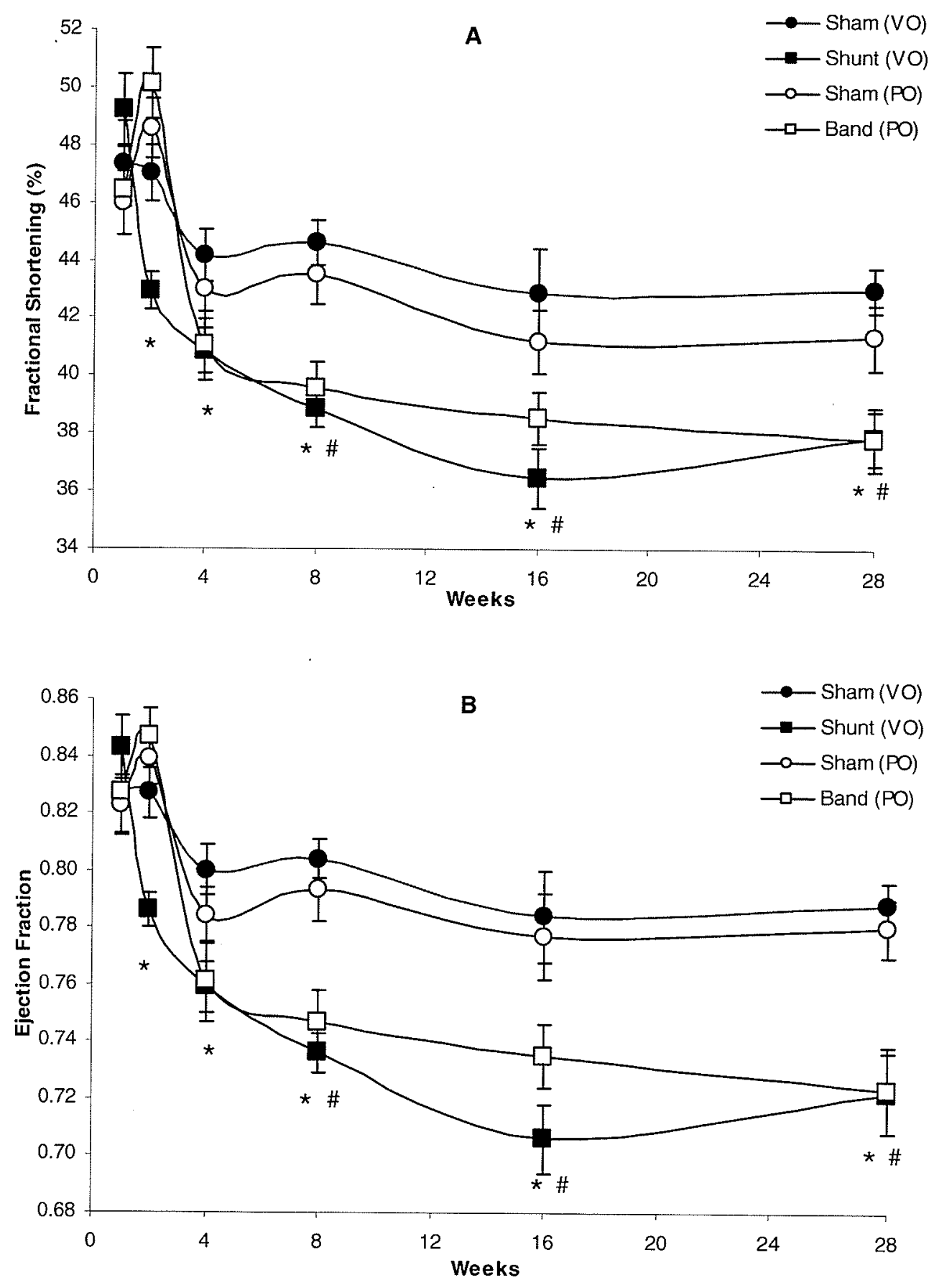

Figure 3. Fractional shortening (A) and ejection fraction (B) in pressure overload (PO) and volume overload (VO). \# $\mathrm{P}<0.05$ vs. sham (PO); * $\mathrm{P}<0.05$ vs. sham (VO). 

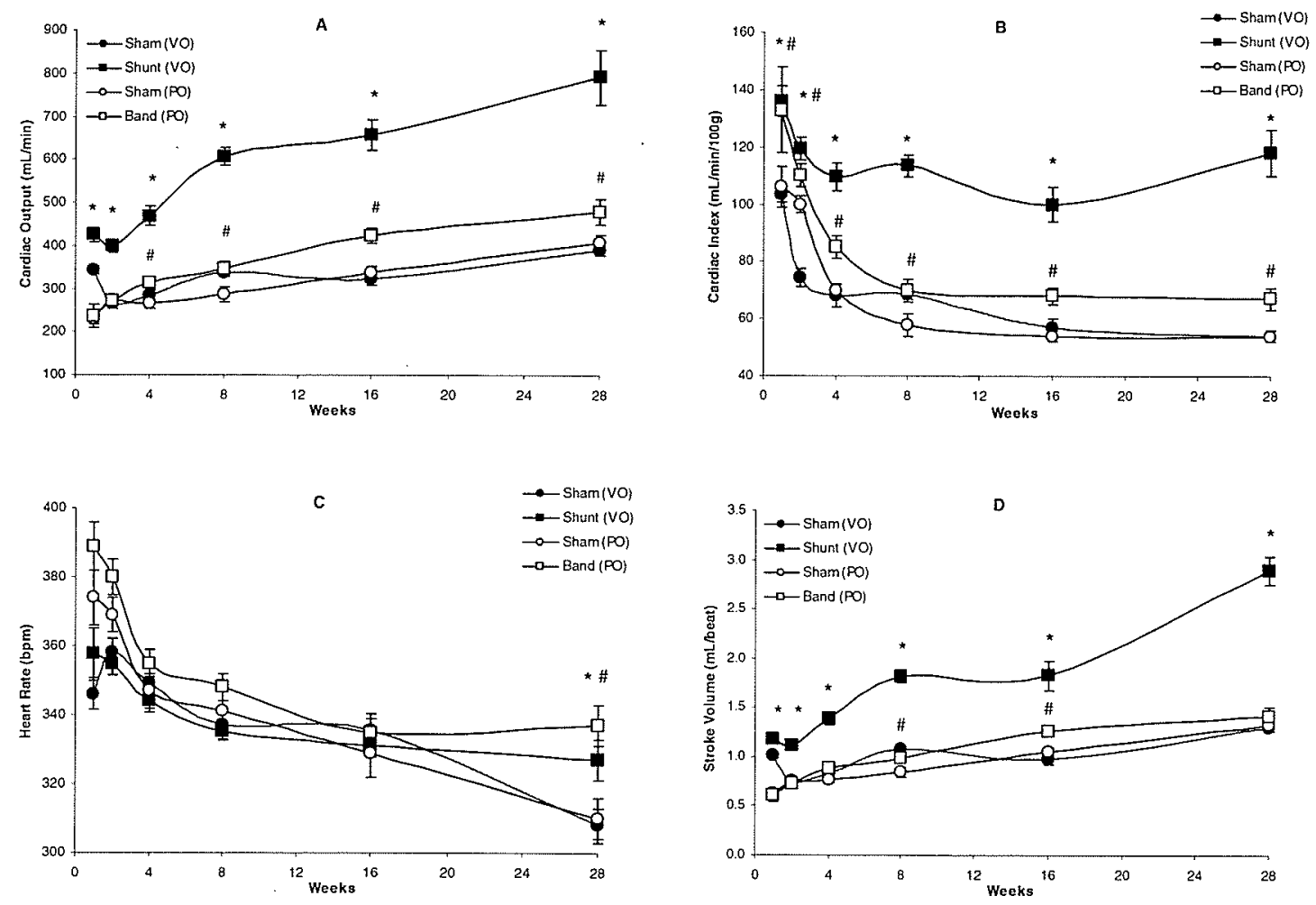

Figure 4. Cardiac output (A), cardiac index (B), heart rate (C) and stroke volume (D) in pressure overload (PO) and volume overload (VO). \# $\mathrm{P}<0.05$ vs. sham $(\mathrm{PO}) ;{ }^{*} \mathrm{P}<0.05$ vs. sham (VO). 


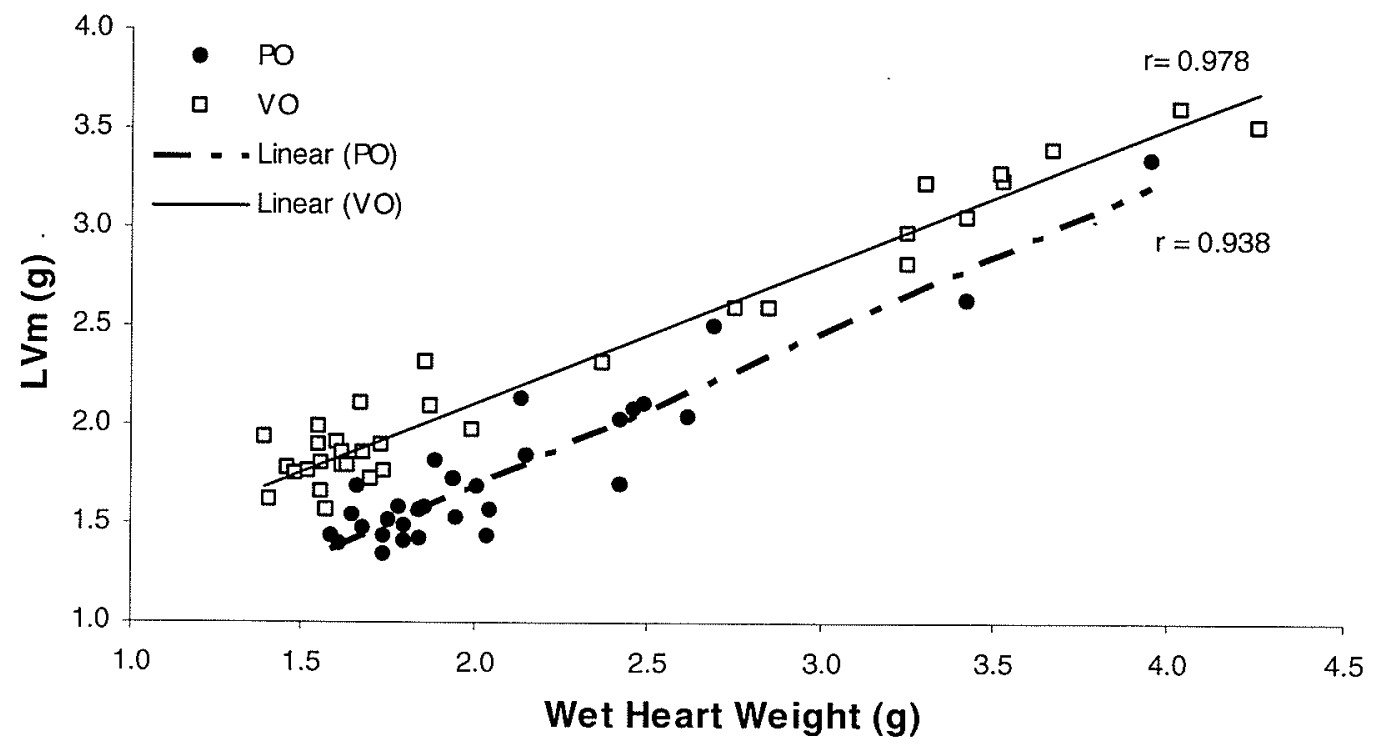

Figure 5. Linear regression analysis of left ventricular mass $(\mathrm{LVm})$ values versus wet heart weights collected at the 28 -week time point. PO, pressure overload; VO, volume overload. 

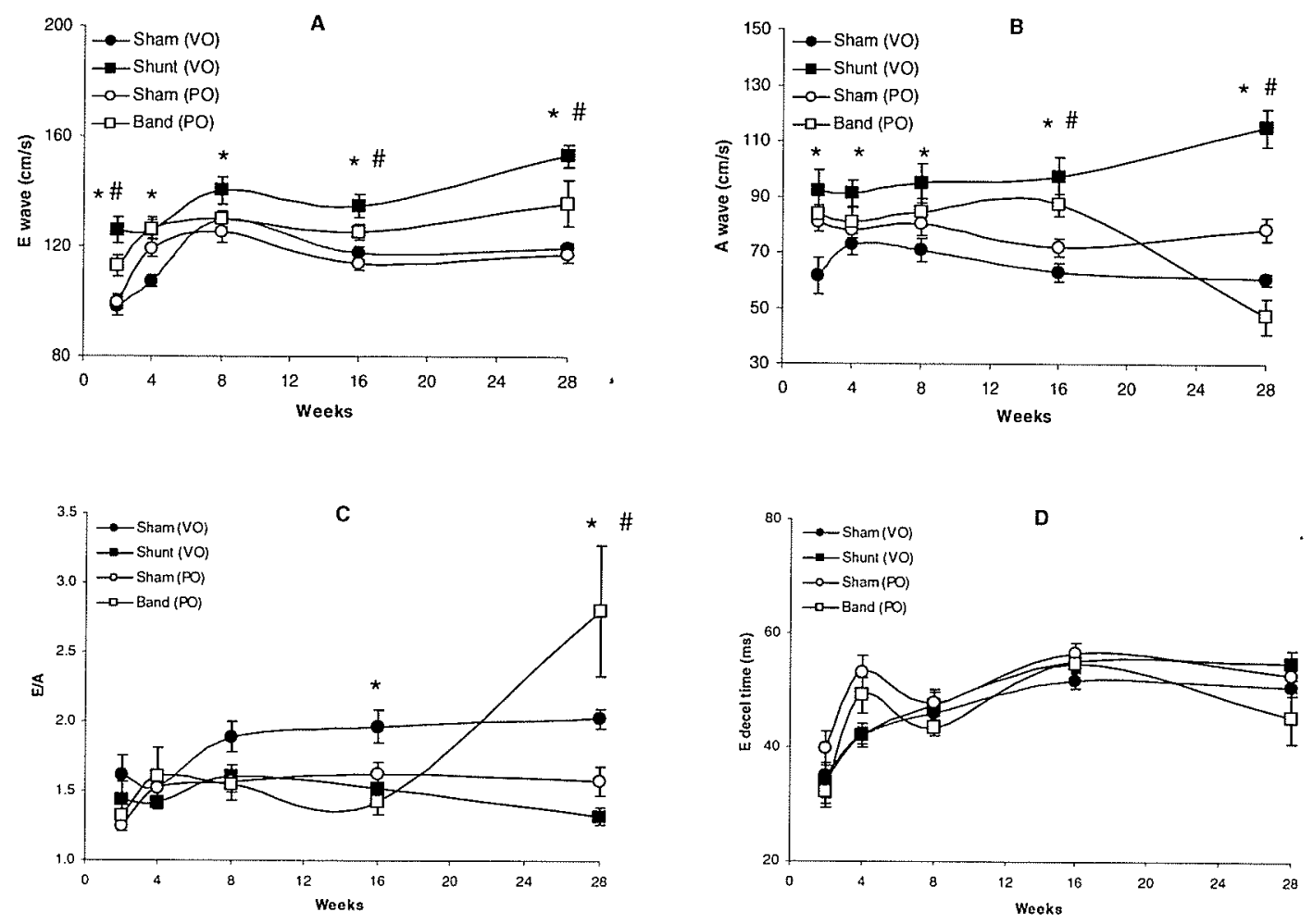

Figure 6. Time course of diastolic parameters obtained by Doppler echocardiography in pressure overload (PO) and volume overload (VO). E wave, peak early diastolic filling velocity; A wave, peak late diastolic filling velocity; $\mathrm{E} / \mathrm{A}$, ratio of early to late peak diastolic filling velocities; $\mathrm{E}$ decel time, $\mathrm{E}$ deceleration time. \# $\mathrm{P}<0.05$ vs. sham $(\mathrm{PO}) ; * \mathrm{P}<0.05$ vs. sham (VO). 

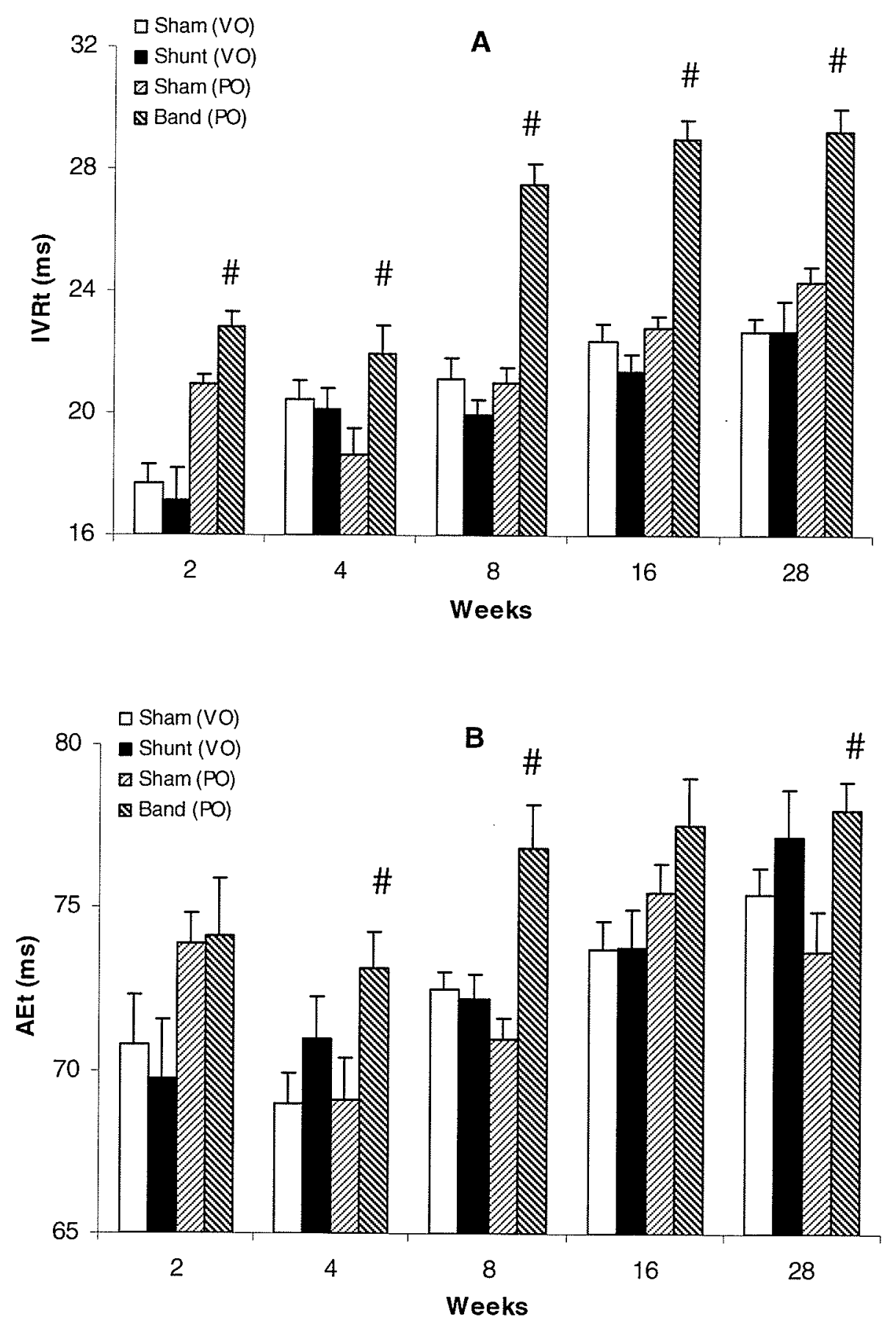

Figure 7. Isovolumic relaxation time (IVRt) (A) and aortic ejection time (AEt) (B) in pressure overload (PO) and volume overload (VO) models obtained by Doppler echocardiography using the apical 5-chamber view. \# $\mathrm{P}<0.05$ vs. sham (PO). 


\section{DISCUSSION}

Responses to PO and VO begin to occur in a similar manner, with the development of hypertrophy that leads to a compensatory phase which is followed by a subsequent decompensatory stage (heart failure). However, transition into failure has been difficult to demonstrate in animal models $(103,104)$ and is often inconsistent (105). Moreover, the specific mechanisms responsible for the progression of hypertrophy and its transition into heart failure are still unknown (105). For this reason, we conducted an extensive serial echocardiographic analysis of both PO and VO rats in order to gain a better understanding of the structural and functional changes that occur from the onset of cardiac hypertrophy through to heart failure. In addition, we examined the differential changes that occurred between the two models.

Our findings indicate that PO in rats led to the development of concentric hypertrophy of the LV, low CO and general systolic dysfunction. Diastolic dysfunction was also observed as indicated by poor compliance and reduced myocardial relaxation capabilities. VO in rats similarly led to the rapid onset of LV hypertrophy that was eccentric in nature. High $\mathrm{CO}$ and systolic dysfunction were apparent, while diastolic function and compliance of the ventricle was unchanged or enhanced in VO rats. Some rats from each model progressed into congestive heart failure, and this occurred at different time points. Therefore, the contributing factors that lead from compensated hypertrophy to overt heart failure in either model are unclear. 
Rat models of hypertrophy that lead to heart failure have been used extensively for studies involving cardiac function and related biochemical changes. Modification of the technique in 1990 (76) has lead to wide use of the aortocaval shunt model and is now well-established in studies mimicking clinically relevant models of VO hypertrophy $(105,106)$. Abdominal aortic banding is also a well-established model for inducing hypertrophy due to PO in animals and it has been used extensively for many decades (65-67).

Early and progressive increases in heart weight along with consistently elevated HBW ratios observed in our study suggest the early initiation and continuous development of hypertrophy in both PO and VO models. Further, the larger increases observed in these parameters in $\mathrm{VO}$ compared to $\mathrm{PO}$ were indicative of the differential types of hypertrophy (concentric and eccentric) that occur between models (7). Increased wet-to-dry weights combined with ascites found in the abdominal cavity indicated that congestion of the lungs and the transition to heart failure arose with greater frequency in VO rats compared with PO rats at 28 weeks. Thus we noted that PO rats did not progress as far as VO rats into the later stages of heart failure at 28 weeks. To our knowledge, this is a novel finding, and few long-term time course studies of general characteristics have been performed in rats subjected to either aortocaval shunt (106) or aortic banding (99).

In recent years, echocardiography has become a well-established method of assessing cardiac structure and function in both human and veterinary medicine (78). In light of recent technological advances, the resolution capabilities of 
ultrasound systems have allowed for more accurate analyses in humans and in animals as small as rats $(38,74,82-88)$ and mice $(89,90)$. Echocardiography is versatile, safe, painless, non-invasive and most importantly an in vivo procedure that allows for serial analyses on virtually any animal model (86). It is far superior and more physiologically relevant than invasive techniques that open the chest cavity and intubate vessels (90). Such techniques require time-consuming surgeries with subsequent euthanasia and thus offer no opportunity for time course studies.

Earlier studies have examined the effects of PO or VO on cardiac structure and function via echocardiography in dogs, cats and mice $(68,107,108)$. Numerous studies have also assessed cardiac structure and function in rats subjected to PO $(82,84,88,99,109-112)$ and VO $(37,38,73,113-117)$. To date, few conspecific comparative echocardiographic studies of PO versus VO using any animal model have been performed (118-120), and long-term serial analyses have not been carried out. Modesti et al. (118) conducted a short-term study in pigs that showed early cardiac adaptations, whereas studies by Carabello et al. (119) and Plehn et al. (120) examined PO versus VO at single time points in rabbits and dogs, respectively.

A recent study assessed M-mode and Doppler echocardiographic values in normal male rats using a comparable anesthetization protocol and an identical ultrasound machine and probe as used in our investigation (121). Although no time course was assessed, their study showed reliable reproducibility with data 
corresponding to values obtained in our study conducted on rats with similar body weights.

A strong correlation between $\mathrm{LVm}$ and wet heart weight was observed in this study; however, M-mode echocardiographic determination of $\mathrm{LVm}$ is relatively accurate yet highly overestimated in rats (122). Our regression analysis showed two parallel lines, with the VO line shifted to the left relative to the PO line. This suggests that VO rats had a greater degree of overestimation of $\mathrm{LVm}$ compared to PO rats, which may be explained by differences in LV geometry between models. Echocardiographic calculation of LVm assumes that the LV chamber is spherical (78), which is more so the case in concentric hypertrophy than in eccentric hypertrophy. Eccentric hypertrophy, as demonstrated in our study, caused the LV chamber to be more oval-shaped than spherical, as one could imagine if converting Figure $1 \mathrm{C}$ into a three-dimensional model of the LV. This finding has significant clinical implications, considering $L V m$ overestimation has been shown to occur in patients with increased pressure (123) and volume loads on the heart (124). These overestimations of LVm may underestimate disease progression as all echocardiographic values are taken relative to others. However, as the LVm increases, there is a greater degree of LVm overestimation (123).

In this study, VO rats exhibited changes in LV geometry distinct from that observed in PO rats. In VO rats, significant chamber dilatation (increased LVID) with little to no change in IVS or LVPW was indicative of pure eccentric hypertrophy as seen in models of pure VO (8). In PO rats, significant increases in 
LVPW and IVS with only small increases in LVID were indicative of pure concentric hypertrophy which is often seen in the early stages of pure PO. Most PO studies that progress into heart failure show late stage chamber dilatation which signifies the end of the compensatory response and the start of failure (85, $88,99)$. We found that very few PO rats reached such an end stage, as seen by not only the general lack of LV chamber dilatation, but also by the general lack of ascites and congestion of the lungs. However, other early signs of failure did arise, including reduced late diastolic filling velocities as well as reduced thickness of the LVPW. Therefore, it is possible that these subtle characteristics precede the more severe characteristics like ascites and chamber dilatation that could be prominent in the later stages of failure.

In VO, eccentric hypertrophy is caused by myocyte elongation (7), which contributes largely to increases in both the HBW ratio and the LVID. As the thickness of the walls remained virtually constant in this model, evidence points to chamber dilatation as a cause for the increase in heart mass. This may be explained by sarcomeric replication in series, in order to accommodate for chamber dilatation. In PO, other mechanisms were responsible for an increase in heart weight and HBW. As, only slight chamber dilatation occurred in PO, concentric hypertrophy due to myocyte thickening was therefore responsible, as demonstrated by the thickening of the ventricular septal and posterior walls (IVS and LVPW, respectively) (7). 
With regard to systolic function, our results show that significant changes in FS and EF occurred earlier in VO rats than in PO rats. Regardless, both FS and EF slowly declined in each experimental model of heart failure, indicative of progressive systolic dysfunction. Another difference between the two models was that $\mathrm{VO}$ rats maintained an elevated $\mathrm{CI}$, while $\mathrm{PO}$ rats did not, pronouncing the differential changes between models, specifically that VO is a high output model of hypertrophy and failure, while PO is a relatively low output model. As expected, SV in VO rats was elevated, accounting for the increased $\mathrm{CO}$ and corresponding with increases in LVIDd. (See similarities between Figures 2A and 4D). A slight increase in $\mathrm{CO}$ found in PO rats may be attributed to elevated SV, except at the 28-week end point, wherein CO may be affected by elevated HR. Elevated HR in each model could be a compensatory response to maintain adequate $\mathrm{CO}$ in failing hearts.

Throughout the time course of this study, diastolic filling velocities were higher in VO rats than in PO rats. As the $\mathrm{E}$ wave is a marker for post-systolic myocardial relaxation, these results were expected; higher filling velocities equated with greater filling due to chamber dilatation. As well, the ventricular myocytes in VO rats were expected to relax more so than in PO due to both the lack of wall thickening in VO and the presence of fibrosis that is reported to occur in PO (125). The fact that A wave velocity was significantly higher in VO rats suggested better ventricular compliance than in PO rats. Further, at 28 weeks ventricular compliance was greatly reduced in PO likely due to overwhelming 
concentric hypertrophy. Abnormal filling, also represented by altered E/A ratios, was found in PO rats at 28 weeks, which was due to the lowered corresponding peak A wave velocities. This suggested restrictive filling due to elevated filling pressures (38). Other markers for impaired myocardial relaxation such as elevated IVRt also demonstrated the inability of PO rats to relax as quickly and efficiently as VO rats, thus further contributing to diastolic dysfunction. Also, the fact that there were no changes in E decel time, which is a measure of LV stiffness, implies that impaired ventricular relaxation may play a more important role than ventricular stiffness in the progression of PO (126).

While considering the effects of $\mathrm{PO}$ and $\mathrm{VO}$ on cardiac structure and function, one must also consider whether gender differences play a role in the cardiac response to these stimuli. It has been shown in rat studies that females are generally more resistant to hypertrophic stimuli than are males. Gardner et al. (127) showed that both male and female rats display increased LVm values after 8 weeks of VO due to aortocaval shunt, however, male rats had a much greater degree of hypertrophy than did female rats. Male rats also showed significant dilatation, increased compliance and signs of congestive heart failure, while female rats exhibited no changes in these parameters. Despite these alterations, male and female rats had comparable HR, SV and CI values. Similarly, 20 weeks of PO in aortic-banded rats (but not 6 weeks) gave rise to gender-specific responses. However, female rats in this study showed a greater degree of LV hypertrophy than did males. Regardless, males displayed a transition to heart 
failure though late-stage LV dilatation, elevated wall stress and diastolic dysfunction. Male rats also had increased collagen levels compared to females (128). These studies indicate that gender plays a significant role in the response to hypertrophic stimuli, and that the mechanisms underlying female resistance to heart failure should be studied further.

Echocardiography alone cannot distinguish physiological from pathological hypertrophy or the transition that may occur from the former to the later (84). However, data on cardiac structure and function may help to make our understanding of this transition more evident. Further, a better understanding of the mechanisms underlying hypertrophy and cardiac remodelling will allow for intervention and the prevention of heart pathologies. Moreover, understanding the differences between PO and VO hypertrophy, their causes and their consequences, will allow for better diagnosis and more specific interventions in the future. The next step in our research will be to look more closely at the subcellular mechanisms responsible for changes in cardiac contractile function, specifically the $\mathrm{Ca}^{2+}$-handling proteins that have been singled out as critical players in altering cardiac contractility (110).

Our study is novel in that it is the first comparative, serial analysis to be conducted on animals of the same species over a similar time course. We have characterized the onset and progression of hypertrophy and heart failure in two rat models via echocardiography and found that $\mathrm{PO}$ and $\mathrm{VO}$ in rats induced differential changes in cardiac structure and function. 


\section{REFERENCES}

1. Hunter JJ, Chien KR. Signaling pathways for cardiac hypertrophy and heart failure. N Eng J Med. 1999;341;1276-1283.

2. Tamargo J, Lopez-Sendon J. Rationale and clinical evidence for the effects of new pharmacological treatments for heart failure. Rev Esp Cardiol. 2004;57:447-464.

3. Prestle J, Quinn FR, Smith GL. $\mathrm{Ca}^{2+}$-handling proteins and heart failure: novel molecular targets? Curr Med Chem. 2003;10:967-981.

4. Shariff S, Straatman L, Allard M, Ignaszewski A. Novel associations of giant cell myocarditis: two case reports and a review of the literature. Can $J$ Cardiol. 2004;20:557-561.

5. Scognamiglio R, Avoraro A, Negut C, Piccolotto R, Vigili de Kreutzenberg S, Tiengo A. Early myocardial dysfunction in the diabetic heart: current research and clinical applications. Am J Cardiol. 2004;93:17A-20A.

6. Frey N, Olson EN. Cardiac hypertrophy: the good, the bad, and the ugly. Annu Rev Physiol. 2003;65:45-79.

7. Carabello BA. Concentric versus eccentric remodeling. J Card Fail. 2002;8:S258-S263.

8. Carabello BA. Models of Volume overload hypertrophy. J Card Fail. 1996;2:55-64.

9. van Empel VP, De Windt LJ. Myocyte hypertrophy and apoptosis: a balancing act. Cardiovasc Res. 2004;63:487-499. 
10. Palazzuoli A, Bruni F, Puccetti L, Pastorelli, M, Angori P, Pasqui AL, Auteri A. Effects of carvedilol on left ventricular remodeling and systolic function in elderly patients with heart failure. Eur $J$ Heart Fail. 2002;4:765-770.

11. Cohn JN. Current concepts in the treatment of congestive heart failure. Cardiology. 1997;88(Suppl. 2):2-6.

12. Ho KK, Pinsky JL, Kannel WB, Levy D. The epidemiology of heart failure: the Framingham Study. J Am Coll Cardiol. 1993;22:6A-13A.

13. 5-10 a Day for Better Health [article online], 2005. Available from http://www.5to10aday.com/eng/media stats.htm\#b. Accessed 17 January 2005.

14. Katz AM. Physiology of the Heart, $3^{\text {rd }}$ Edition. Lippincott Williams \& Wilkins, Philadelphia, PA, 2001.

15. Katz AM. Heart failure: a hemodynamic disorder complicated by maladaptive proliferative responses. J Cell Mol Med. 2003;7:1-10.

16. Mann DL. Mechanisms and models in heart failure: a combinatorial approach. Circulation. 1999;100:999-1008.

17. Dosh SA. Diagnosis of heart failure in adults. Am Fam Physician. 2004;70:2145-2152.

18. Sherwood L. Human Physiology: from cells to systems, $3^{\text {rd }}$ Edition. Wadsworth Publishing Company, Belmont, CA, 1997. 
19. Maree AO, Fitzgerald DJ. Aspirin and coronary artery disease. Thromb Haemost. 2004;92:1175-1181.

20. Gutierrez C, Blanchard DG. Diastolic heart failure: challenges of diagnosis and treatment. Am Fam Physician. 2004;69:2609-2616.

21. Fatkin D, Graham RM. Molecular mechanisms of inherited cardiomyopathies. Physiol Rev. 2002;82-945-980.

22. Towbin JA, Bowles NE. The failing heart. Nature. 2002;415:227-233.

23. Passoti M, Repetto A, Tavazzi L, Arbustini E. Genetic predisposition to heart failure. Med Clin North Am. 2004;88:1173-1192.

24. Maisch B, Ristic AD, Portig I, Pankuweit S. Human viral cardiomyopathy. Front Biosci. 2003;8:s39-s67.

25. Marian AJ, Roberts R. Molecular genetic basis of hypertrophic cardiomyopathy: genetic markers for sudden death. $J$ Cardiovasc Electrophysiol. 1998;9:88-99.

26. Marian AJ, Roberts R. The molecular genetic basis for hypertrophic cardiomyopathy. J Mol Cell Cardiol. 2001;33:655-670.

27. Elliott P, McKenna WJ. Hypertrophic cardiomyopathy. Lancet. 2004;363:1881-1891.

28. Regan TJ, Ahmed S, Haider B, Moschos C, Weisse A. Diabetic cardiomyopathy: experimental and clinical observations. $N J$ Med. 1994;91:776-778. 
29. Bell DS. Diabetic cardiomyopathy. A unique entity or a complication of coronary artery disease? Diabetes Care. 1995;18:708-714.

30. Srikanthan P, Hsueh W. Preventing heart failure in patients with diabetes. Med Clin North Am. 2004;88:1237-1256.

31. Carabello BA. The relationship of left ventricular geometry and hypertrophy to left ventricular function in valvular heart disease. $J$ Heart Valve Dis. 1995;4(Suppl 2):S132-S138.

32. Carabello BA, Crawford FA Jr. Valvular heart disease. $N$ Engl J Med. 1997:337:32-41.

33. Trines J, Hornberger LK. Evolution of heart disease in utero. Pediatr Cardiol. 2004;25:287-298.

34. Stouffer GA, Lenihan DJ, Lerakis S, Agahtehrani A, Ahn J, Martin RP. Timing of aortic valve surgery in chronic aortic stenosis and regurgitation. Am J Med Sci. 2004;327:348-351.

35. Dorn GW 2nd, Donner R, Assey ME, Spann JF Jr, Wiles HB, Carabello BA. Alterations in left ventricular geometry, wall stress, and ejection performance after correction of congenital aortic stenosis. Circulation. $1988 ; 78: 1358-1364$.

36. Carabello BA. The pathophysiology of mitral regurgitation. $J$ Heart Valve Dis. 2000;9:600-608. 
37. Plante E, Lachance D, Gaudreau M, Drolet MC, Roussel E, Arsenault M. Effectiveness of beta-blockade in experimental chronic aortic regurgitation. Circulation. 2004;110:1477-1483.

38. Plante E, Couet J, Gaudreau M, Dumas M-P, Drolet MC, Arsenault M. Left ventricular response to sustained volume overload from chronic aortic valve regurgitation in rats. $J$ Card Fail. 2003;9:128-140.

39. Groves P. Valve disease: surgery of valve disease: later results and late complications. Heart. 2001;86:715-721.

40. Yock PG, Popp RL. Noninvasive estimation of right ventricular systolic pressure by Doppler ultrasound in patients with tricuspid regurgitation. Circulation. 1984;70:657-662.

41. Singh N, Dhalla AK, Seneviratne C, Singal PK. Oxidative stress and heart failure. Mol Cell Biochem. 1995;147:77-81.

42. Korantzopoulos P, Galaris D, Papaioannides D, Siogas K. The possible role of oxidative stress in heart failure and the potential of antioxidant intervention. Med Sci Monit. 2003;9:RA140-RA145.

43. Gerschman R, Gilbert DL, Nye SW, Dwyer P, Fenn WO. Oxygen poisoning and $\mathrm{x}$-irradiation: a mechanism in common. Science. 1954;119:623-626.

44. Chance B, Sies H, Boveris A. Hydroperoxide metabolism in mammalian organs. Physiol Rev. 1979;59:527-605. 
45. Cantor EJ, Mancini EV, Seth R, Yao XH, Netticadan T. Oxidative stress and heart disease: cardiac dysfunction, nutrition and gene therapy. Curr Hypertens Rep. 2003;5:215-220.

46. Dhalla AK, Singal PK. Antioxidant changes in hypertrophied and failing guinea pig hearts. Am J Physiol. 1994;266:H1280-H1285.

47. Dhalla AK, Hill MF, Singal PK. Role of oxidative stress in transition of hypertrophy to heart failure. J Am Coll Cardiol. 1996;28:506-514.

48. Sorescu D, Griendling KK. Reactive oxygen species, mitochondria, and $\mathrm{NAD}(\mathrm{P}) \mathrm{H}$ oxidases in the development and progression of heart failure. Congest Heart Fail. 2002;8:132-140.

49. Cox MJ, Hawkins UA, Hoit BD, Tyagi SC. Attenuation of oxidative stress and remodeling by cardiac inhibitor of metalloproteinase protein transfer. Circulation. 2004;109:2123-2128.

50. Tappia PS, Hata T, Hozaima L, Sandhu MS, Panagia V, Dhalla NS. Role of oxidative stress in catecholamine-induced changes in cardiac sarcolemmal $\mathrm{Ca}^{2+}$ transport. Arch Biochem Biophys. 2001;387:85-92.

51. Temsah RM, Netticadan T, Chapman D, Takeda S, Mochizuki S, Dhalla NS. Alterations in sarcoplasmic reticulum function and gene expression in ischemic-reperfused rat heart. Am J Physiol. 1999;277:H584-H594. 
52. Itoh S, Yanagishita T, Aoki S, Koba S, Iwata T, Ishioka H, Arata H, Mukae S, Geshi E, Konno N, Katagiri T, Utsumi H. Generation of free radicals and the damage done to the sarcoplasmic reticulum during reperfusion injury following brief ischemia in the canine heart. Jpn Circ J. 1999;63:373-378.

53. Scoote $\mathrm{M}$, Williams AJ. Myocardial calcium signalling and arrhythmia pathogenesis. Biochem Biophys Res Commun. 2004;322:1286-1309.

54. Fabiato A. Calcium-induced release of calcium from the cardiac sarcoplasmic reticulum. Am J Physiol. 1983;245:C1-C14.

55. Fowler MR, Naz JR, Graham MD, Bru-Mercier G, Harrison SM, Orchard $\mathrm{CH}$. Decreased $\mathrm{Ca}$ extrusion via $\mathrm{Na} / \mathrm{Ca}$ exchange in epicardial left ventricular myocytes during compensated hypertrophy. Am J Physiol Heart Circ Physiol. 2004 Dec 22; [Epub ahead of print].

56. Hudecova S, Tillinger A, Mravec B, Kvetnansky R, Krizanova S. Effect of 6-hydroxydopamine on the gene expression of $\mathrm{Na}^{+} / \mathrm{Ca}^{2+}$ exchanger in the rat heart. Gen Physiol Biophys. 2004;23:307-313.

57. Bito V, Heinzel FR, Weidemann F, Dommke C, van der Velden J, Verbeken E, Claus P, Bijnens B, De Scheerder I, Stienen GJ, Sutherland GR, Sipido KR. Cellular mechanisms of contractile dysfunction in hibernating myocardium. Circ Res. 2004;94:794-801.

58. Benitah JP, Kerfant BG, Vassort G, Richard S, Gomez AM. Altered communication between L-type calcium channels and ryanodine receptors in heart failure. Front Biosci. 2002;7:e263-e275. 
59. Wehrens XH, Lehnart SE, Marks AR. Intracellular calcium release channels and cardiac disease. Annu Rev Physiol. 2004 Jul 21; [Epub ahead of print].

60. Haghighi K, Gregory KN, Kranias EG. Sarcoplasmic reticulum CaATPase-phospholamban interactions and dilated cardiomyopathy Biochem Biophys Res Commun. 2004;322:1214-1222.

61. MacLennan DH, Kranias EG. Phospholamban: a crucial regulator of cardiac contractility. Nat Rev Mol Cell Biol. 2003;4:566-577.

62. Wehrens XH, Marks AR. Molecular determinants of altered contractility in heart failure. Ann Med. 2004;36(Suppl 1):70-80.

63. Richey PA, Brown SP. Pathological versus physiological left ventricular hypertrophy: a review. J Sports Sci. 1998;16:129-141.

64. Pelliccia A, Maron BJ, De Luca R, Di Paolo FM, Spataro A, Culasso F. Remodeling of left ventricular hypertrophy in elite athletes after long-term deconditioning. Circulation. 2002;105:944-949.

65. Hiyoshi H, Yayama K, Takano M, Okamoto H. Stimulation of cyclic GMP production via $\mathrm{AT} 2$ and $\mathrm{B} 2$ receptors in the pressure-overloaded aorta after banding. Hypertension. 2004;43:1258-1263.

66. Ganguly PK, Lee S-L, Beamish RE, Dhalla NS. Altered sympathetic system and adrenoceptors during the development of cardiac hypertrophy. Am Heart J. 1989;118:520-525. 
67. Malik AB, Geha AS. Role of adrenergic mechanisms in the development of cardiac hypertrophy. Proc Soc Exp Biol Med. 1975;150:796-800.

68. Liao Y, Ishikura F, Beppu S, Asakura M, Takashima S, Asanuma H, Sanada S, Kim J, Ogita H, Kuzuya T, Node K, Kitakaze M, Hori M. Echocardiographic assessment of LV hypertrophy and function in aorticbanded mice: necropsy validation. Am J Physiol. 2002;282:H1703-H1708.

69. Collins KA, Korcarz CE, Shroff SG, Bednarz JE, Fentzke RC, Lin H, Leiden JM, Lang RM. Accuracy of echocardiographic estimates of left ventricular mass in mice. Am J Physiol. 2001;280:H1954-H1962.

70. Orito K, Yamane T, Kanai T, Fujii Y, Wakao Y, Matsuda H. Time course sequences of angiotensin converting enzyme and chymase-like activities during development of right ventricular hypertrophy induced by pulmonary artery constriction in dogs. Life Sci. 2004;75:1135-1145.

71. Oyama MA, Sisson DD, Bulmer BJ, Constable PD. Echocardiographic estimation of mean left atrial pressure in a canine model of acute mitral valve insufficiency. $J$ Vet Intern Med. 2004;18:667-672.

72. Bauman RP, Rembert JC, Greenfield JC Jr. Myocardial blood flow in awake dogs with chronic tricuspid regurgitation. Basic Res Cardiol. 1998;93:63-69.

73. Murakami K, Mizushige K, Noma T, Kimura S, Abe Y, Matsou H. Effects of perindopril on left ventricular remodeling and aortic regurgitation in rats assessed by echocardiography. Angiology. 2000;51:943-952. 
74. Arsenault M, Plante E, Drolet MC, Couet J. Experimental aortic regurgitation in rats under echocardiographic guidance. J Heart Valve Dis. 2002;11:128-134.

75. Flaim SF, Minteer WJ, Nellis SH, Clark DP. Chronic arteriovenous shunt: evaluation of a model for heart failure in rat. Am J Physiol. 1979;236:H698H704.

76. Garcia R, Diebold S. Simple, rapid, and effective method of producing aortocaval shunts in the rat. Cardiovasc Res. 1990;24:430-432.

77. Deroubaix E, Folliguet T, Rucker-Martin C, Dinanian S, Boixel C, Validire P, Daniel P, Capderou A, Hatem SN. Moderate and chronic hemodynamic overload of sheep atria induces reversible cellular electrophysiologic abnormalities and atrial vulnerability. J Am Coll Cardiol. 2004;44:19181926.

78. Coatney RW. Ultrasound Imaging: Principles and applications in rodent research. ILAR J. 2001;42:233-247.

79. Isaaz K. Tissue Doppler imaging for the assessment of left ventricular systolic and diastolic functions. Curr Opin Cardiol. 2002;17:431-442.

80. Guéret P, Bensaïd J. L'échocardiographie: instrument d'évaluation quantitative du remodelage ventriculaire. Arch Mal Coeur Vaiss. $1991 ; 84: 21-27$.

81. Wood MJ, Picard MH. Utility of echocardiography in the evaluation of individuals with cardiomyopathy. Heart. 2004;90:707-712. 
82. Salemi VMC, Pires MD, Cestari IN, Cestari IA, Picard MH, Leirner AA, Mady C. Echocardiographic assessment of global ventricular function using the myocardial performance index in rats with hypertrophy. Artif Organs. 2004;28:332-337.

83. Slama M, Susic D, Varagic J, Ahn J, Frohlich ED. Echocardiographic measurement of cardiac output in rats. Am J Physiol. 2003;284:H691-H697.

84. Derumeaux G, Mulder P, Richard V, Chagraoui A, Hafeh C, Bauer F, Henry J-P, Thuillez C. Tissue Doppler imaging differentiates physiological from pathological pressure-overload left ventricular hypertrophy in rats. Circulation. 2002;105:1602-1608.

85. Heyen JRR, Blasi ER, Nikula K, Rocha R, Daust HA, Frierdich G, Van Vleet JF, De Ciechi P, McMahon EG, Rudolph AE. Structural, functional, and molecular characterization of the SHHF model of heart failure. Am $J$ Physiol. 2002; 283:H1775-H1784.

86. Ono K, Masuyama T, Yamamoto K, Doi R, Sakata Y, Nishikawa, N, Mano T, Kuzuya T, Tadeka H, Hori M. Echo Doppler assessment of left ventricular function in rats with hypertensive hypertrophy. $J$ Am Soc Echocardiogr. 2002;15:109-117.

87. Mihm MJ, Seifert JL, Coyle CM, Bauer JA. Diabetes related cardiomyopathy time dependent echocardiographic evaluation in an experimental rat model. Life Sci. 2001;69:527-542. 
88. Litwin SE, Katz SE, Weinberg EO, Lorell BH, Aurigemma GP, Douglas PS. Serial echocardiographic-Doppler assessment of left ventricular geometry and function in rats with pressure-overload hypertrophy. Circulation. 1995;91:2642-2654.

89. Hoit BD. Spectral and color M-mode Doppler in genetically altered mice. Minerva Cardioangiol. 2003;51:609-618.

90. Tanaka N, Dalton N, Mao L, Rockman HA, Peterson KL, Gottshall KR, Hunter JJ, Chien KR, Ross J. Transthoracic echocardiography in models of cardiac disease in the mouse. Circulation. 1996;94:1109-1117.

91. Watt RH. Congenital heart disease: an overview of the condition and treatment options. Lippincotts Case Manag. 2004;9:205-208.

92. Tsutsui JM, Xie F, Porter TR. The use of microbubbles to target drug delivery. Cardiovasc Ultrasound. 2004;2:23-29.

93. Alexandrov AV, Molina CA, Grotta JC, Garami Z, Ford SR, Alvarez-Sabin J, Montaner J, Saqqur M, Demchuk AM, Moye LA, Hill MD, Wojner AW. Ultrasound-enhanced systemic thrombolysis for acute ischemic stroke. $N$ Engl J Med. 2004;351:2170-2178.

94. Polak JF. Ultrasound energy and the dissolution of thrombus. $N$ Engl $J$ Med. 2004;351:2154-2155.

95. Slama M, Susic D, Varagic J, Frohlich ED Diastolic dysfunction in hypertension. Curr Opin Cardiol. 2002;17:368-373. 
96. Shapiro LM, Gibson DG. Patterns of diastolic dysfunction in left ventricular hypertrophy. Br Heart J. 1988;59:438-445.

97. Schaefer A, Klein G, Brand B, Lippolt P, Drexler H, Meyer GP. Evaluation of left ventricular diastolic function by pulsed Doppler tissue imaging in mice. J Am Soc Echocardiogr. 2003;16:1144-1149.

98. Masuyama T, Yamamoto K, Sakata Y, Doi R, Nishikawa N, Kondo H, Ono K, Kuzuya T, Sugawara M, Hori M. Evolving changes in Doppler mitral flow velocity pattern in rats with hypertensive hypertrophy. $J$ Am Coll Cardiol. 2000;36:2333-2338.

99. Norton GR, Woodiwiss AJ, Gaasch WH, Mela T, Chung ES, Aurigemma GP, Meyer TE. Heart failure in pressure overload hypertrophy. J Am Coll Cardiol. 2002;39:664-671.

100. Verdecchia P, Angeli F, Pittavini L, Gattobigio R, Benemio G, Porcellati C. Regression of left ventricular hypertrophy and cardiovascular risk changes in hypertensive patients. Ital Heart J. 2004;5:505-510.

101. Ikonomidis I, Tsoukas A, Parthenakis F, Gournizakis A, Kassimatis A, Rallidis L, Nihoyannopoulos P. Four year follow up of aortic valve replacement for isolated aortic stenosis: a link between reduction in pressure overload, regression of left ventricular hypertrophy, and diastolic function. Heart. 2001;86:309-316. 
102. Sahn DJ, DeMaria A, Kisslo J, Weyman A. Recommendations regarding quantitation in M-mode echocardiography: results of a survey of echocardiographic measurements. Circulation. 1978;58:1072-1083.

103. Mann DL, Spann JF, Cooper G. Basic mechanisms and models in cardiac hypertrophy: pathophysiological models. Mod Concepts Cardiovasc Dis. $1988 ; 57: 7-11$.

104. Aoyago T, Fujii AM, Flanagan MF, Arnold LW, Brathwaite KW, Colan SD, Mirsky I. Transition from compensated hypertrophy in intrinsic myocardial dysfunction during development of left ventricular pressureoverload in conscious sheep: systolic dysfunction precedes diastolic dysfunction. Circulation. 1993;88:2415-2425.

105. Brower GL, Janicki JS. Contribution of ventricular remodeling to pathogenesis of heart failure in rats. Am J Physiol. 2001;280:H674-H683.

106. Wang X, Ren B, Liu S, Sentex E, Tappia PS, Dhalla NS. Characterization of cardiac hypertrophy and heart failure due to volume overload in the rat. $J$ Appl Physiol. 2003;94:752-763.

107. Gaasch WH, Zile MR, Hoshino PK, Apstein CS, Blaustein AS. Stressshortening relations and myocardial blood flow in compensated and failing canine hearts with pressure-overload hypertrophy. Circulation. $1989 ; 79: 872-883$. 
108. Pollack PS, Bailey BA, Budjak R, Fernandez E, Houser SR. Progressive feline pressure-overload: noninvasive assessment correlates with abnormalities in single cells. Am J Physiol. 1993;264:H1307-H1314.

109. Chung ES, Perlini S, Aurigemma GP, Fenton RA, Dobson Jr. JG, Meyer TE. Effects of chronic adenosine uptake blockade on adrenergic responsiveness and left ventricular chamber function in pressure overload hypertrophy in the rat. J Hypertens. 1998; 16:1813-1822.

110. del Monte F, Butler K, Boecker W, Gwathmey JK, Hajjar RJ. Novel technique for aortic banding followed by gene transfer during hypertrophy and heart failure. Physiol Genomics. 2002;9:49-56.

111. Li J, Li P, Feng X, Li Z, Hou R, Han C, Zhang Y. Effects of losartan on pressure overload-induced cardiac gene expression profiling in rats. Clin Exp Pharmacol Physiol. 2003;30:827-832.

112. Zaha V, Grohmann J, Gobel H, Geibel A, Beyersdorf F, Doenst T. Experimental model for heart failure in rats--induction and diagnosis. Thorac Cardiovasc Surg. 2003;51:211-215.

113. Sullebarger JT, D'Ambra PM, Clark LC, Thanikarry L, Fontanet HL. Effect of digoxin on ventricular remodeling and responsiveness of betaadrenoceptors in chronic volume overload. J Cardiovasc Pharmacol Ther. 1998;3:281-290. 
114. Dolgilevich SM, Siri FM, Atlas SA, Eng C. Changes in collagenase and collagen expression after induction of aortocaval fistula in rats. Am $J$ Physiol. 2001;281:H207-H214.

115. Shigematsu H, Hirooka Y, Eshima K, Shihara M, Tagawa T, Takeshita A. Endogenous angiotensin II in the NTS contributes to sympathetic activation in rats with aortocaval shunt. Am J Regulatory Integrative Comp Physiol. 2001;280:R1665-R1673.

116. de Paiva SA, Zornoff LA, Okoshi MP, Okoshi K, Matsubara LS, Matsubara $\mathrm{BB}$, Cicogna AC, Campana AO. Ventricular remodeling induced by retinoic acid supplementation in adult rats. Am J Physiol. 2003;284:H2242$\mathrm{H} 2246$.

117. McGowan BS, Scott CB, Mu A, McCormick RJ, Thomas DP, Margulies KB. Unloading-induced remodeling in the normal and hypertrophic left ventricle. Am J Physiol. 2003;284:H2061-2068.

118. Modesti PA, Vanni S, Bertolozzi I, Cecioni I, Polidori G, Paniccia R, Bandinelli B, Perna A, Liguori P, Boddi M, Galanti G, Serneri GG. Early sequence of cardiac adaptations and growth factor formation in pressureand volume-overload hypertrophy. Am J Physiol. 2000;279:H976-H985.

119. Carabello BA, Zile MR, Tanaka R Cooper IV G. Left ventricular hypertrophy due to volume overload versus pressure overload. Am $J$ Physiol. 1992; 263:H1137-H1144. 
120. Plehn JF, Foster E, Grice WN, Huntington-Coats M, Apstein CS. Echocardiographic assessment of LV mass in rabbits: models of pressure and volume overload hypertrophy. Am J Physiol. 1993;265:H2066-H2072.

121. Watson LE, Sheth M, Denyer RF, Dostal DE. Baseline echocardiographic values for adult male rats. J Am Soc Echocardiogr. 2004;17:161-167.

122. Reffelmann T, Kloner RA. Transthoracic echocardiography in rats. Basic Res Cardiol. 2003;98:275-284.

123. Stewart GA, Foster J, Cowan M, Rooney E, McDonagh T, Dargie HJ, Rodger RSC, Jardine AG. Echocardiography overestimates left ventricular mass in hemodialysis patients relative to magnetic resonance imaging. Kidney International. 1999;56:2248-2253.

124. Kühl HP, Hanrath P, Franke A. M-mode echocardiography overestimates left ventricular mass in patients with normal left ventricular shape: a comparative study using three-dimensional echocardiography. Eur $J$ Echocardiography. 2003;4:313-319.

125. Namba T, Tsutsui H, Tagawa H, Takahashi M, Saito L, Kozai T, Usui M, Imanaka-Yoshida T, Takeshita A. Regulation of fibrillar collagen gene expression and protein accumulation in volume-overloaded cardiac hypertrophy. Circulation. 1997;95:2448-2454. 
126. Dent CL, Bowman AW, Scott MJ, Allen JS, Lisauskas JB, Janif M, Wickline SA, Kovács SJ. Echocardiographic characterization of fundamental mechanisms of abnormal diastolic filling in diabetic rats with a parameterized diastolic filling formalism. $J$ Am Soc Echocardiogr. 2001;14:1166-1172.

127. Gardner JD, Brower GL, Janicki JS. Gender differences in cardiac remodeling secondary to chronic volume overload. $J$ Card Fail. 2002;8:101-107.

128. Douglas PS, Katz SE, Weinberg EO, Chen MH, Bishop SP, Lorell BH. Hypertrophic remodeling: gender differences in the early response to left ventricular pressure overload. JACC. 1998;32:1118-1125. 